the Total Environment

Elsevier Editorial system(tm) for science of

Manuscript Draft

Manuscript Number: STOTEN-D-18-00298R1

Title: Integration of Environmental Aspects in Modelling and Optimisation of Water Supply Chains

Article Type: Research Paper

Keywords: hydrological balances; water supply chains; spatially explicit MILP; supply reliability; game theory

Corresponding Author: Professor Lazaros Papageorgiou,

Corresponding Author's Institution: University College London

First Author: Mariya Koleva

Order of Authors: Mariya Koleva; Andres Calderon; Di Zhang; Craig Styan; Lazaros Papageorgiou

Abstract: Climate change becomes increasingly more relevant in the context of water systems planning. Tools are necessary to provide the most economic investment option considering the reliability of the infrastructure from technical and environmental perspectives.

Accordingly, in this work, an optimisation approach, formulated as a spatially-explicit multi-period Mixed Integer Linear Programming (MILP) model, is proposed for the design of water supply chains at regional and national scales. The optimisation framework encompasses decisions such as installation of new purification plants, capacity expansion, and raw water trading schemes. The objective is to minimise the total cost incurring from capital and operating expenditures. Assessment of available resources for withdrawal is performed based on hydrological balances, governmental rules and sustainable limits. In the light of the increasing importance of reliability of water supply, a second objective, seeking to maximise the reliability of the supply chains, is introduced. The epsilon-constraint method is used as a solution procedure for the multi-objective formulation. Nash bargaining approach is applied to investigate the fair trade-offs between the two objectives and find the Pareto optimality. The models' capability is addressed through a case study based on Australia. The impact of variability in key input parameters is tackled through the implementation of a rigorous global sensitivity analysis (GSA). The findings suggest that variations in water demand can be more disruptive for the water supply chain than scenarios in which rainfalls are reduced. The frameworks can facilitate governmental multi-aspect decision making processes for the adequate and strategic investments of regional water supply infrastructure.

Response to Reviewers: Please see attached file for reply to reviewers' points 


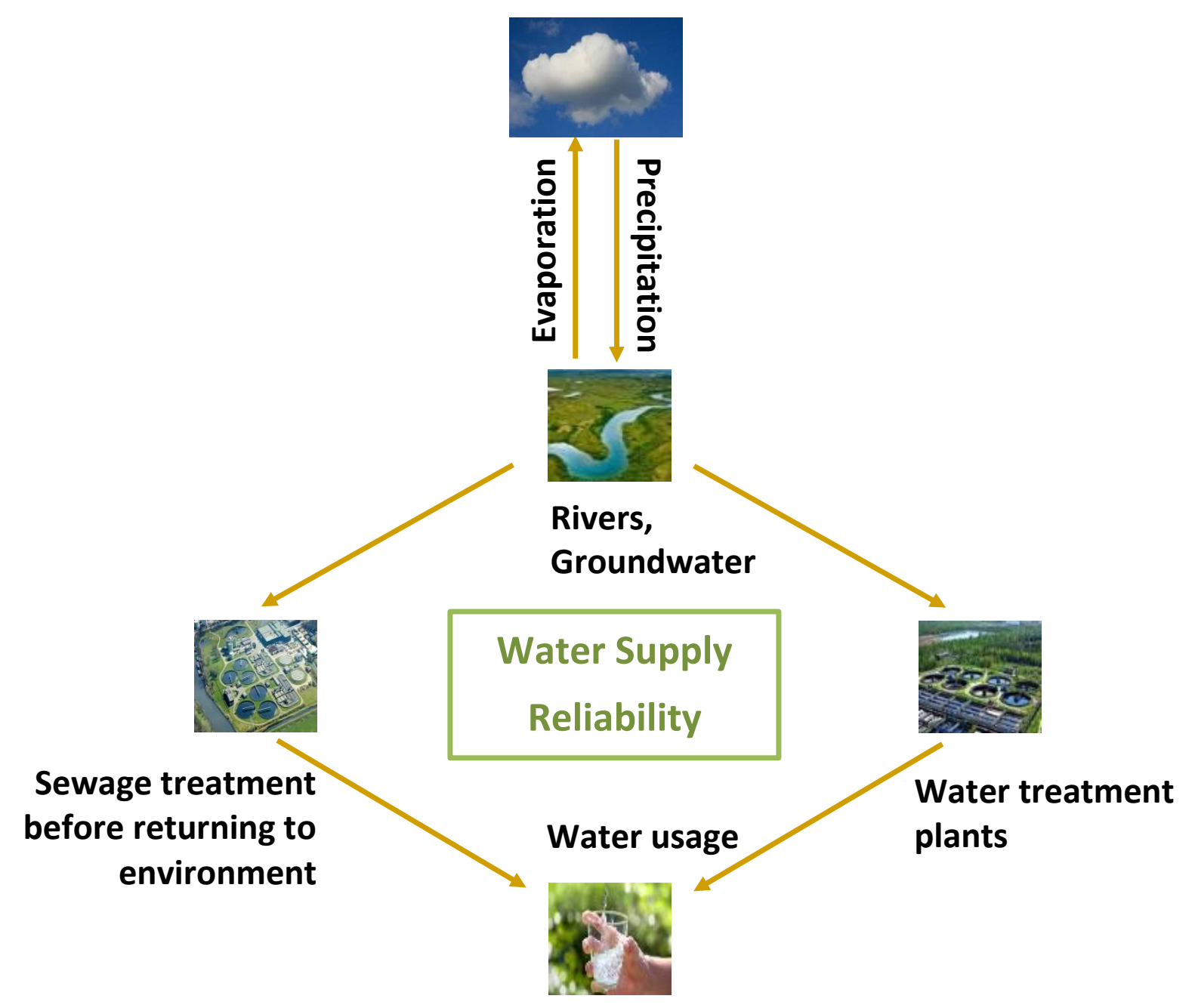


${ }^{*}$ Highlights (for review : 3 to 5 bullet points (maximum 85 characters including spaces per bullet point)

Highlights (for review)

Highlights for manuscript entitled "Integration of Environmental Aspects in Modelling and Optimisation of Water Supply Chains"

- The proposed framework encompasses climatic, governmental and sustainability constraints.

- Cost and water supply reliability are addressed through multi-objective optimisation.

- Trade-off between cost and reliability is studied through game theory using Nash equilibrium.

- The framework is applied to a case study based on Australia. 


\title{
Integration of Environmental Aspects in Modelling and Optimisation of Water Supply Chains
}

\author{
Mariya N. Kolevaa,b, Andrés J. Calderón ${ }^{\mathrm{a}}$, Di Zhanga ${ }^{\mathrm{a}}$, Craig A. Styan ${ }^{\mathrm{b}}$, Lazaros G. Papageorgiou ${ }^{\mathrm{a}, *}$ \\ ${ }^{a}$ Centre for Process Systems Engineering, Dept. of Chemical Engineering, UCL, Torrington Place, London, WC1E 7JE, United \\ Kingdom \\ ${ }^{b}$ School of Energy and Resources, UCL Australia, 220 Victoria Square, Adelaide, South Australia, 5000, Australia
}

\begin{abstract}
Climate change becomes increasingly more relevant in the context of water systems planning. Tools are necessary to provide the most economic investment option considering the reliability of the infrastructure from technical and environmental perspectives. Accordingly, in this work, an optimisation approach, formulated as a spatially-explicit multi-period Mixed Integer Linear Programming (MILP) model, is proposed for the design of water supply chains at regional and national scales. The optimisation framework encompasses decisions such as installation of new purification plants, capacity expansion, and raw water trading schemes. The objective is to minimise the total cost incurring from capital and operating expenditures. Assessment of available resources for withdrawal is performed based on hydrological balances, governmental rules and sustainable limits. In the light of the increasing importance of reliability of water supply, a second objective, seeking to maximise the reliability of the supply chains, is introduced. The epsilon-constraint method is used as a solution procedure for the multi-objective formulation. Nash bargaining approach is applied to investigate the fair trade-offs between the two objectives and find the Pareto optimality. The models' capability is addressed through a case study based on Australia. The impact of variability in key input parameters is tackled through the implementation of a rigorous global sensitivity analysis (GSA). The findings suggest that variations in water demand can be more disruptive for the water supply chain than scenarios in which rainfalls are reduced. The frameworks can facilitate governmental multi-aspect decision making processes for the adequate and strategic investments of regional water supply infrastructure. Keywords: hydrological balances, water supply chains, spatially explicit MILP, supply reliability, game theory
\end{abstract}

\section{Introduction}

Concurrent population growth, economic development and climate change are the main drivers for the acute and chronic water shortages Morrison et al. [2009], Dizikes [2016], US Environmental Protection Agency [2016].

To mitigate and adapt to the changes, authorities examine strategic options to enhance the supply-demand

*Corresponding author

Email address: 1.papageorgiou@ucl.ac.uk (Lazaros G. Papageorgiou) 
management for a long term resilience. Planning for 15-35 years ahead by water industries ensures adequate facilities and infrastructure in place to maintain the security of supplies throughout those periods. The gap between supply and demand can be filled by diversifying the portfolio of options for water supply. For instance, alternative sources of water, investing in storage and production capacities, expanding market participants and water quality grade trading options, alongside with interconnectivity and distribution losses minimisation, should be included in the list [Pricewaterhouse Coopers, 2010].

Besides the conventional surface water sources diverted from rivers and lakes, and groundwater extracted from aquifers, non-conventional sources such as seawater, brackish and recycled water have been taking place in the source mix for water provision. Although treated wastewater is not the publicly accepted source for drinking, it is essential for other, non-potable applications in order to meet overall demand. On the other hand, non-conventional sources require more extensive treatment and therefore, more expensive purification techniques hence, they often serve as a back-up during prolong droughts [Pricewaterhouse Coopers, 2010].

As a limited resource, water usage by an entity can affect its availability to another. Conflict and competition among entities, when it comes to resources, is likely to arise hence, a coordinated allocation system is sought. Such a system is represented by water markets, operating on the principle of 'cap and trade' system where:

- the cap illustrates the water available for sustainable extraction

- market participants hold water abstraction rights or licences which are a part of the total available pool

- the rights and the allocations in every season can be traded among participants

- the trading price is set by the participants in the water market

Such water trading schemes exist in Spain, Chile, South Africa, Australia, UK and some states in the United States of America. Water market participants may include users such as industry, irrigation operators, urban water utilities, etc. [Australian Government, 2016a]. In a regulated market, the availability of water would govern the extent of trade of an entity with another entity. A thorough way of assessing water availability is by taking into account the environmental flows, such as precipitation, evaporation, run-off, infiltration, etc., which can be expressed by an inflow-outflow water balance for a particular system in a region.

Affordable and secure water supply is crucial for the domestic and industrial conduct of daily activities Zhu et al. 2015. Water supply reliability can be defined as the probability of meeting demand or the probability of not meeting demand subtracted by one [Hawk, 2003]. Over a time period, reliability becomes the frequency or the quantity of supply shortfalls measured against demand. Temporal reliability most often involves system failures, which are related to mathematical problems with higher granularity, for instance, operation problems. For designing the water supply chain, the focus of interest is a quantification of how much of the demand will not be met. Hence, the choice of reliability assessment in the current work is volumetric. Governments and 
water entities are facing numerous challenges providing an adequate supply reliability. Such challenges are climate change, population growth, environmental regulations, decaying infrastructure and calamities. Enhancing trading, and expanding storage and treatment capacities would increase supply reliability [Shamir, 1987, Goulter, 1995 Zhu et al. 2015. Therefore, satisfactory water management planning and design have to be in place California Urban Water Agencies, 2012]. In order to address an adequate management system, the current work considers water supply chain design, entailing resources allocation under hydrological balances and water trading, and supply reliability both as single and multi-objective optimisation frameworks.

Much attention has been paid to optimisation techniques in water supply chains (WSC) as they provide a systematic way of making decisions on future investments. Ray et al. [2010] addressed the issue through a linear programming model for the minimum cost configuration of future water supply, wastewater disposal, and reuse options for the city of Beirut. Koleva et al. 2016, 2017] proposed linear and non-linear programming models for the optimal design of water and water-related treatment processes. Li et al. [2009] developed a multi-stream, multi-reservoir and multi-period mixed integer linear programming (MILP) model that was integrated into an inexact multistage joint-probabilistic programming to investigate the decision under uncertainty and surplus-flow diversions. Kondili et al. [2010] presented a mathematical framework for the water supply design taking into consideration various sources and users as well as possible conflicting demand over a time period. The model was applied to a case study for the Aegean Islands. Liu et al. [2010, 2011, 2012], Liu [2011], Padula et al. [2013] and Padula [2015] proposed mathematical formulations for the minimisation of proposed installations of plants, storages, pipelines applied on specific case studies. Matrosov et al. [2015] looked at multi-objective optimisation for water supplies focused on London and based on $\varepsilon$ - dominance non - dominated sorting genetic algorithms and simulation. Saif and Almansoori 2014 suggested a multi-period MILP model for the desalination supply chains with decisions on locations for new and extended plants, storages and pipelines. Al-Nory and Graves [2013. proposed a mathematical programme for the design of desalination supply chain taking into consideration locations of new plants installations. Guerra et al. [2016] and Saif and Almansoori [2016] integrated water management in different supply chain contexts. Loucks et al. [2005] and Joshi and Joshi [2016] contributed with comprehensive insight into water resources planning, modelling and management and advances in supply chain.

Various works on modelling of water resources allocation and pricing have been published in Brebbia [2015]. Heydari and Qaderi [2015] developed an MILP model for the multi-purpose reservoirs operation. Veintimilla-Reyes et al. [2016] introduced a spatio-temporal mixed integer formulation for water allocation. Yildiran et al. [2015] formulated an MILP model for the short-term scheduling of water reservoirs considering day-ahead market prices. He et al. 2015] proposed an MILP model and applied Benders decomposition method for dynamic resource allocation and traffic assignment in evacuation network. Hughes [1976] developed an optimisation framework, based on integer programming, on solving algorithms for water resources planning problems. Li et al. [2016] 
presented a stochastic quadratic model applicable to discrete, fuzzy and random input data for water resources allocation with a case study on Heihe River basin, China. Roozbahani et al. [2015] proposed an approach and a mathematical model for the allocation of water resources among stakeholders. Zeng et al. [2014] constructed a model based on inexact credibility-constrained programming method to investigate the efficiency of water trading under multiple uncertainties. Britz et al. [2013] proposed a Multiple Optimisation Problems with Equilibrium Constraints (MOPEC) for hydro-economic river basin models to account for the decentralised access to water use. Qureshi et al. [2013] introduced a mathematical programming model with an application on agricultural water use in Murray-Darling Basin, Australia. Rinaudo et al. [2016] proposed a price-endogenous model for the trading activity and equilibrium prices in urban water markets. Blanco and Viladrich-Grau [2014] analysed the outcomes of irrigating water trading scheme through a nonlinear mathematical programming model, applied to a case study in Spain. Erfani et al. [2014] presented an optimisation model for short-term pair-wise spot-market trading of surface water rights. It is based on a node-arc multi-commodity approach following a transaction tracking method [Erfani et al. 2013]. Peng et al. [2015] proposed an optimisation model for water transfer decision making process considering shortages in reservoirs of both, recipients and donors.

Reliability of water supply has increasingly become the focus of a number publications. Damelin et al. [1972] first introduced the concept of reliability of water supply in a simulation context. Barlow [1984 presented a historical angle of mathematical theory of reliability. Peng et al. [2015] presented a mathematical formulation for water allocations accounting for reliability. Reliability has also been the focus of numerous works which consider jt alongside calamities and changing climate Wang and Au, 2009, Simonit et al. 2015, Clark et al. 2015, Yoo et al. 2016].

Multi-objective optimisation approaches have been the focus of a large number of literature works. Pokharel [2008] was one of the first works to use multi-objective optimisation in supply chain network design where twoobjective decision-making model for the choice of suppliers and warehouses for a supply chain network design was proposed. Amodeo et al. [2009] integrated evolutionary algorithms and supply chain simulation for the maximisation of customer service level and the total inventory cost. Liu and Papageorgiou [2013] developed an MILP model for cost, responsiveness and customer service level using $\varepsilon$-constraint method and lexicographic minimax method as solution approaches. Chen and Andresen 2014 applied a weighted-sum approach minimising costs, emissions, and employee injuries in a supply chain.

When more than one factor determines the design of the water management system, besides an optimal, a fair strategic decision can be taken by applying game theory. Game theory can be utilised for various applications, such as engineering, life sciences, management and economics. Games can be collaborative, when the best strategies for the players are to cooperate, and competitive, when the players can maximise their outcome if they do not take into consideration the outcomes of the rest of the players. Games can also be simultaneous and sequential, 
when the decisions of the players are taken at the same time or one after another, like in a leader - follower type of game. The former often implies the information is not well known and in cases of the latter, normally the follower makes a decision based on the action of the leader. This leads to dealing with perfect and imperfect information games. Recent works on game theory in mixed integer programming have been classified qualitatively based on the aforementioned applications. A typical leader - follower game is the Stackelberg game which has been the chosen strategy in different literature sources YYue and You 2014, Bard et al. 2000, Yang et al., 2015 Pita et al. 2010. Yin, 2013]. Zhang et al. [2013] developed mathematical models for fair electricity pricing microgrid, scheduling, planning, and in Zhang et al. 2017] - carbon capture and storage following cooperative Nash approach Nash 1950]. Nash equilibrium has been applied in supply chains and scheduling [Zamarripa et al. 2013. Gjerdrum et al., 2002, Banaszewski et al., 2013, Pira and Artigues, 2016, Ortiz-Gutierrez et al., 2015 [Tushar et al. 2014]. General supply chain game theory and transfer prices have been covered by Simchi-Levi et al. [2004], Rosenthal [2008]. Additionally, Shelton [1997], Tambe [2012] have published exhaustive compilation books on game theory, security and markets. Madani [2010] compiled a literature review on game theory concepts applied to water resources management. The research suggested non-cooperative game theory can be a powerful tool for managing real conflicts without the necessity of accurate quantitative information. Sechi et al. [2011] suggested a decision making tool using game theory to determine fair water pricing with sustainability principles. M. Daumas [2009] proposed a mathematical model for the theory of cooperative games for transferable utilities (TU). [Souza Filho et al. 2008] investigated game theory on water users' strategic behaviour. Nikjoofar and Zarghami [2013] simulated water distribution networks using multiobjective optimisation and game theory.

To the best of the authors knowledge, there is no work which integrates in detail the concepts of supply chains, allocations, reliability and game theory. The current work addresses this gap by not only combining all the aforementioned separate concepts but also considering the entire water cycle with legislative regulations altogether in a mixed integer linear programming (MILP) formulation. The paper, thus, aims at investigating how to consolidate those multiple-aspects into a single optimisation framework. A multiple number of sources, users, trading and time periods are geographically considered. The locations and capacities for surface, groundwater, seawater plants and the trading volumes of each source among regions are to be optimised. Then, a multiobjective optimisation is formulated for the simultaneous minimisation of total cost and maximisation of reliability using $\varepsilon$-constraint method. In order to identify the fairest operating point along the Pareto curve, we propose the implementation of game theory, specifically, the bargaining approach. A global sensitivity analysis (GSA) is implemented to address the impact of uncertainty associated with input data on the water supply chain. Four parameters were selected for this purpose as follows: rainfalls, capital investments, facilities efficiency, and demand. The rest of this work is structured as follows: Section 2 sets out the problem statement whose mathematical formulation is presented in Section 3 The applicability of the model is investigated in a case study, described in 
Section 4 followed by results and discussion in Section 5 Finally, concluding remarks are made in Section 6

\section{Problem statement}

The supply chain problem at hand entails strategic decisions for the allocation of water resources, procurement and treatment of sources types, locations and capacities expansions for dams and treatment plants, trading directions and volumes.

A geographical area is considered where water demands can be met by surface water, groundwater and seawater. Options such as reclaimed water and individually collected rain water are disregarded in this work. The area is divided into sub-regions, or states, based on their federal governance and autonomy. The water demand for each territory is estimated according to the population predictions and consumption patterns per capita. Additionally, the water demand varies seasonally, peaking in summer and plummeting in winter. Spring and autumn seasons are characterised with moderate consumption volumes. Regulated water services of every region are provided by water suppliers to meet the urban water demand, which occurs from residential, commercial, municipal and industrial usage. A state might not be able to meet its regional demand consequently, it should identify a strategy for dealing with water deficit. In case source water is in deficit, trading among regions is considered. Only surface and groundwater can be traded. On the other hand, if storage or production capacities are not sufficient, optimal decisions for the capacity and location for the expansion of existing plants, and installation of new dams and plants are made.

Water is diverted from lakes and reservoirs, and abstracted from aquifers taking into account the seasonal hydrological cycles and sustainable yields (withdrawals) within the territories. Water balances, or budgets, are performed over the total regional available water storages. Reservoirs, dams, ponds, lakes and groundwater aquifers are referred to as storages. The inflows into the storages are the seasonal precipitations, run-off, streamflows and recharge while the outflows consist of evaporation, discharge and diverted/abstracted volumes. Precipitation refers to the rainfall that falls directly onto the storage area. Run-off represents excess of moisture turning into the streamflow from the catchments or drainage basins to the storage. Streamflows refer to the river flowing into the storage. Evaporation is the direct evaporation from the storage surface, while discharge refers to the river stream leaving the system. Diversions are the water flows withdrawn for human usage. Groundwater discharge or seepage is ignored due to being a minor component and due to the scarce historical data available. As a matter of convenience, the streamflows for different river systems in a region have been summed up. It is assumed that dead storage comprises $10 \%$ of the water storage capacity. Further, by a rule of thumb, $10 \%$ of the rainfall in drainage basins infiltrates to become groundwater inflow. Climatic data is extracted for the entire planning horizon reflecting fluctuations in the weather conditions and therefore, el Niño and la Niña events, which occur 
every 5-7 years. Oceans and seas are not taken into account in water budgets due to their abundance.

In every region there are rights for maximum water sources diversions/extractions. They are called target allocations, or entitlements, and apply for surface water and groundwater. In a season when availability in storage is sufficient, the allocations in a region can reach target allocations. The amount of water that has been allocated for withdrawal and has not been used in a given year can be rolled to the next year unless regulations oblige a return to the abstraction basin. After the resources are withdrawn, they are processed in surface water treatment plants (SWTP), groundwater treatment plants (GWTP) and seawater desalination plants (SDP) which operate with different efficiencies. Then, the product water is distributed for urban usage, after which it is assumed $60 \%$ of that water is collected as sewerage. The wastewater is then treated in wastewater treatment plants (WWTP) and returned as recharge. It must be noted that no decisions are made with respect to WWTPs and the concept is introduced merely to close the water cycle. A scheme, representing the problem, is illustrated in Fig. 1 .

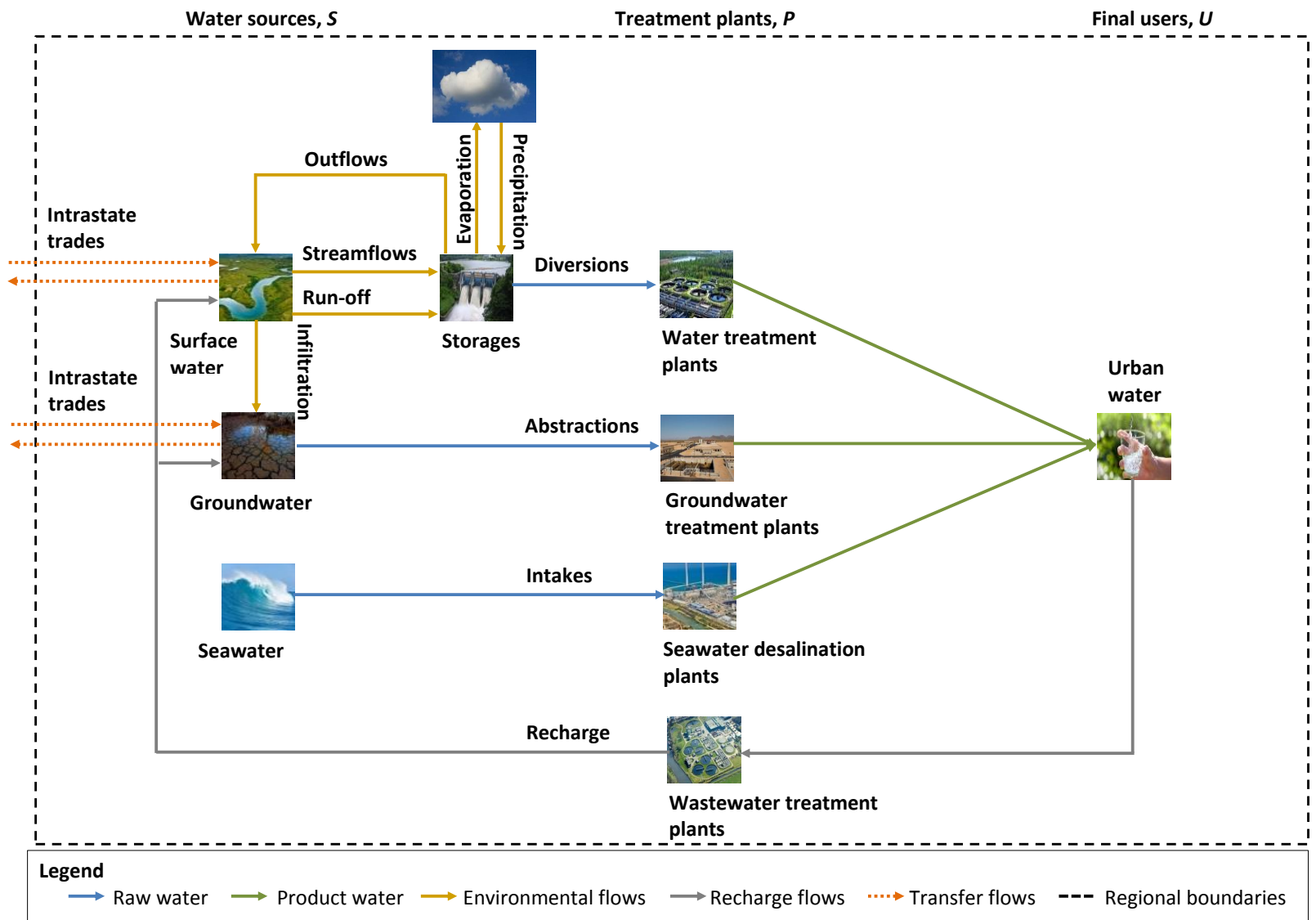

Figure 1: Schematic representation of the water network system

Thus, the problem description with key parameters can be stated below.

Given: 
- geographical divisions into regions/states/territories

- planning time horizon, e.g. a 25 - year horizon

- water sources, i.e. surface water (sw), groundwater (gw), seawater, or desalinated water, (dw), etc.

- final water uses, i.e. urban (uw), rural (rw), etc., and seasonal demand over planning horizon

- regional and seasonal climatic data, i.e. precipitation, evaporation, run-off, streamflows

- initial water storages in drainage basins and reservoirs

- geographical distribution, capacities, operating efficiencies, and operating and capital cost parameters of existing and potential dams and plants

- maximum allocated water sources per end-use, i.e. entitlements

- trading topology and prices options

- inflation and discount factors

- regional sustainable diversions/abstractions

- penalty costs for not meeting demand

Determine:

- available water sources for diversion/abstraction

- procurement rate for each water source and end-use water production rate

- trading and carry-over flowrates of surface and groundwater

- water supply reliability

- location and capacities of new dams and plants installations, and existing plants expansions

So as to: minimise the annualised total cost for operating and building the network proposed subject to environmental, operational, logical and economic constraints. Initially, the supply chain problem is formulated as a spatially-explicit multi-period Mixed Integer Linear Programming (MILP) model. Then, a second objective is added for the maximisation of reliability, hence, the model becomes multi-objective.

\section{Mathematical formulation}

In this section the mathematical formulation is presented first, as a single objective problem, in Section 3.1 where key constraints are the water cycle balances, procurement and production constraints, logical constraints, supply reliability, and operating and capital expenditures. The objective is to minimise the total cost for the entire region for the planning horizon. Next, reliability of supply is added as a second objective function and solved using an $\varepsilon$-constraint method in Section 3.2.1. and game theory in Section 3.2.2. A multi-objective optimisation for minimising total cost and maximising reliability of supply is going to reveal the extent the supply chain network 
design is influenced by both factors. Additionally, game theory will provide a fair trade-off between the two objectives.

\subsection{Monolithic approach}

\subsubsection{Hydrological balances}

The estimation of water availability in storage rests on the inflows into the system, $R_{i g t q}$, recharges, $R C_{i g t q}$ and the total storage from the previous season, $S_{\text {igt,q-1 }}$. $R_{\text {igtq }}$ represents a summation of rainfall, run-off and streamflows for surface water, and infiltrated rainfall for groundwater, shown in Eq.(1) and Eq.(2).

$$
R_{\text {igtq }}=R_{\text {igtq }}^{\text {ain }}+R_{\text {igtq }}^{\text {unoff }}+R_{\text {igtq }}^{\text {iver }}, \forall i=" s w ", g, t, q
$$

where $R_{\text {igtq }}^{\text {ain }}$ is the direct rainfall to the reservoir, $R_{\text {igtq }}^{\text {unoff }}$ is the run-off seeping into the reservoirs and $R_{\text {igtq }}^{\text {iver }}$ represents the stream inflows to the storage. It is assumed that run-off occurring in one region fills the reservoirs in the same region and no other neighbouring regions. A proportion of the rainfall which falls onto the mainland, $L R_{i g t q}^{a i n}$, infiltrates into the ground and becomes an inflow for aquifers.

$$
R_{\text {igtq }}=r^{\text {infl }} \cdot L R_{\text {igtq }}^{\text {ain }}, \forall i=" g w ", g, t, q
$$

where $r^{i n f l}$ is the fraction of the rainfall that infiltrates. Simultaneously, the total outflows from the system are the evaporation losses, $L_{i g t q}$, outflows, $O_{i g t q}$ and allocated water, $A_{i g t q}$. It is assumed no additional losses occur for both, surface water and groundwater systems. The inflows and outflows are illustrated in Fig. 2 and yearly formulations are shown in Eq. (3) and Eq. (4), respectively. 


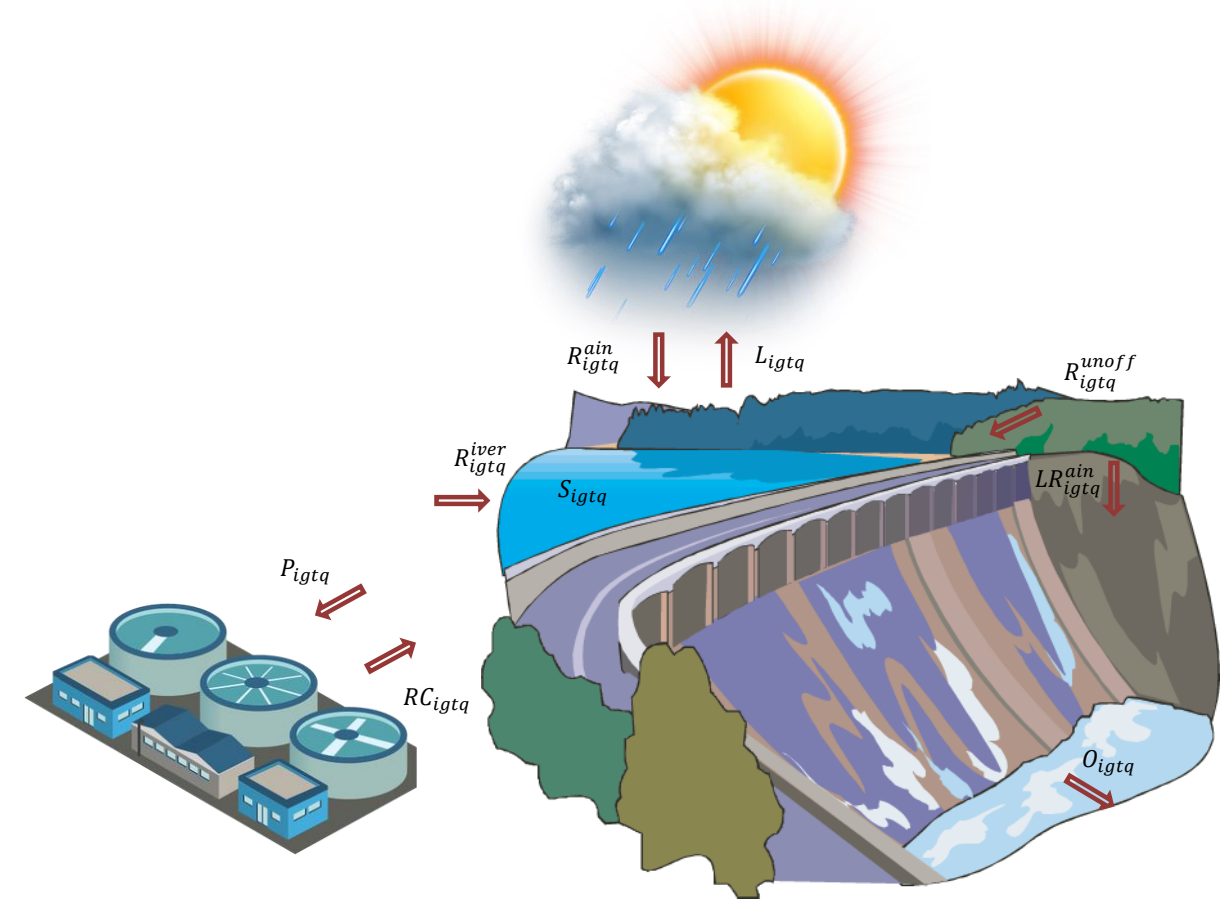

Figure 2: Inflows (rainfall, run-off, river streamflows, recharges) and outflows (evaporation, withdrawals, outflows) from a reservoir system

$$
\begin{array}{r}
\left.D S_{i g t q}\right|_{i=" s w "}+W S_{i g t q}=\left.D S_{i g t, q-1}\right|_{i=" s w "}+W S_{i g t, q-1}+R_{i g t q}+R C_{i g t q}+A C_{i g t q}-\left.L_{i g t q}\right|_{i=" s w "}-A_{i g t q}- \\
\left.O_{i g t q}\right|_{i=" s w ", \forall i \in L W, g, t, q>1} \\
\left.D S_{i g t q}\right|_{i=" s w "}+W S_{i g t q}=\left.D S_{i g, t-1, q}\right|_{i=" s w ", q=4}+\left.W S_{i g, t-1, q}\right|_{q=4}+R_{i g t q}+R C_{i g t q}+A C_{i g t q}-\left.L_{i g t q}\right|_{i=" s w "}-A_{i g t q}- \\
\left.O_{i g t q}\right|_{i=" s w ",}, \forall i \in L W, g, t, q=1
\end{array}
$$

where $L W$ is a set containing the inland water sources, i.e. surface water and groundwater. Surface water storages include dams, and natural storages, i.e. lakes and wetlands. In this work, a cumulative term to refer to both, human-made and natural storages, is storage or reservoir. Aquifers are the only storage for groundwater which occurs in its natural form. The sum of dams' storage, $D S_{i g t q}$, and natural storage, $W S_{i g t q}$ add up to the total storage, $S_{i g t q}$, shown in Eq. (5).

$$
S_{i g t q}=\left.D S_{i g t q}\right|_{i=" s w "}+W S_{i g t q}, \forall i \in L W, g, t, q
$$


where at $t=0$ and $q=0$ the storage is the summation of the initial reservoirs' and lakes' storages. A representation of the time disretisation in years, seasons and their sequence is demonstrated in Fig. 3.

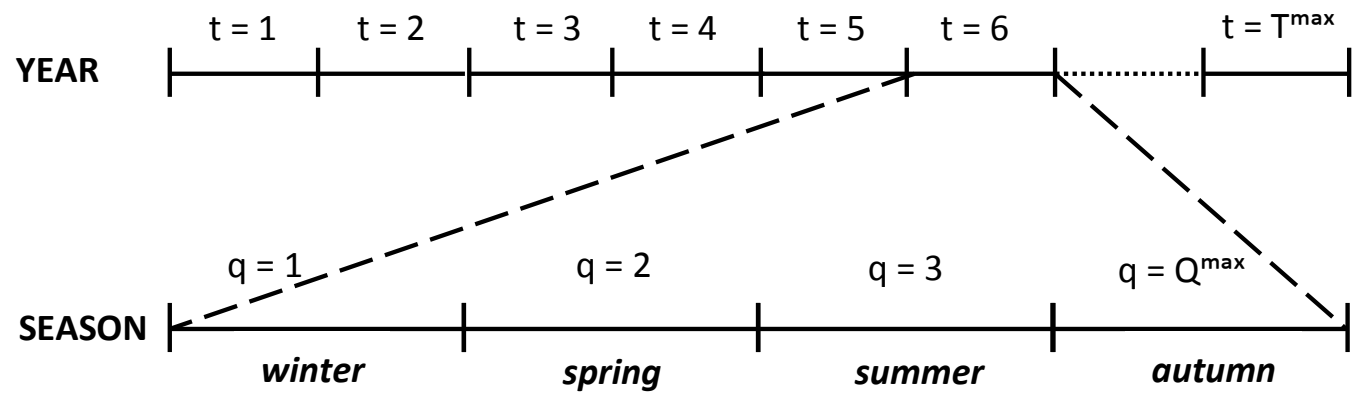

Figure 3: Visualisation of year and seasonal time discretisation. The sequence of seasons $q$ depends on the start and end of the fiscal year $t$ a government uses

The maximum natural storage capacity per region, $W S_{i g}^{\max }$, should not be exceeded in any year $t$ and season $q$ in order to prevent overflows (Eq. (6)).

$$
W S_{i g t q} \leq W S_{i g}^{\max }, \forall i={ }^{\prime} s w ", g, t, q
$$

\subsubsection{Supply - demand balances}

Fig. 4 delineates the water supply chain flows for given regions $g$ and $g^{\prime}$.

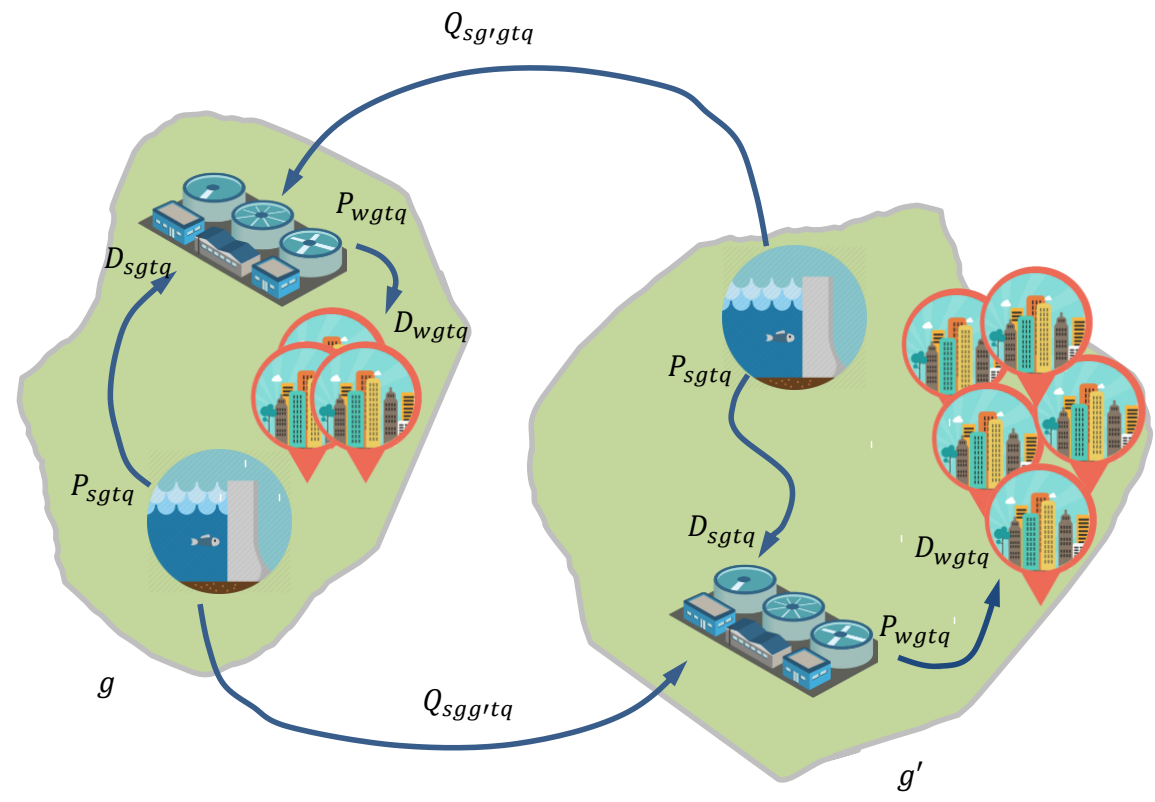

Figure 4: A supply-demand flow diagram, including withdrawals, production, distribution and trading between region $g$ and region $g^{\prime}$ 
Eq.(7) represents those interactions through a global mass balance equation which entails the water type flows $i(I=S \cup W)$ at every node of the WSC: withdrawals of raw water $s, P_{s g t q}$, according to purification plant intake demand, $D_{\text {sgtq }}$, and production of final grade water $w, P_{w g t q}$, to meet populated centres demand, $D_{w g t q}$. It also takes into account $Q_{i g g^{\prime} t q}$ and $Q_{i g^{\prime} g t q}$, which are the traded flows sent to and received from other regions, respectively.

$$
D_{i g t q}+\sum_{g^{\prime} \in \eta_{i g g^{\prime}}} Q_{i g g^{\prime} t q}-P D_{i g t q}=P_{i g t q}+\sum_{g^{\prime} \in \eta_{i g^{\prime} g}} Q_{i g^{\prime} g t q}, \forall i, g, t, q
$$

where $\eta_{i g g^{\prime}}$ and $\eta_{i g^{\prime} g}$ define the allowed directions of flow from region to region. Regions with hydrological or physical connectivity are selected for trading. When a demand cannot be met by the treatment plants, water flows, $P D_{\text {igtq }}$, are allowed to compensate for the shortage. These flows are penalised in the objective function.

\subsubsection{Procurement constraints}

The amounts of diverted surface water and extracted groundwater are determined by the allocated water rights, or allocations $A_{\text {igtq }}$, a region $g$ is allowed to withdraw in year $t$ and season $q$. The carry-over volumes, $A C_{i g t q}$, are the amounts rolled over from one season to the next after ensuring enough water is set aside for meeting the regional demand. The seasonal and annual expressions are shown in Eq.(8) and Eq.(9), respectively.

$$
\begin{gathered}
A C_{i g t q}=A C_{i g t, q-1}+A_{i g t q}-P_{i g t q}, \forall i \in L W, g, t, q>1 \\
A C_{i g t q}=\left.A C_{i g, t-1, q}\right|_{q=4}+A_{i g t q}-P_{i g t q}, \forall i \in L W, g, t, q=1
\end{gathered}
$$

The central principle behind carry-over is that unused water can be carried over, but it must not displace inflows that support new allocations. Only inland water $L W$ is affected by allocation rules due to the associated finiteness with those resources. The allocations are calculated on the basis of the water rights, or the entitlements ent $i_{\text {gt }}$, which are the maximum water volumes that can be withdrawn in year $t$.

$$
\sum_{q} A_{i g t q} \leq e n t_{i g t}, \forall i \in L W, g, t
$$

The entitlements are treated as parameters based on the assumption that they are automatically renewed from year to year. In this work, it is assumed that maximum $100 \%$ of the entitlements can be received in a year $t$.

Additionally, a limitation is considered that a region $g$ can trade water with other regions $g^{\prime}$ only when $g$ 
satisfies its regional demand from the seasonal allocations available (Eqs. 111, (13)).

$$
\begin{gathered}
\sum_{g^{\prime} \in \eta_{i g g^{\prime}}} Q_{i g g^{\prime} t q} \leq e n t_{i g t} \cdot B_{i g t q}, \forall i \in L W, g, t, q \\
P_{i g t q} \leq D_{i g t q}+e n t_{i g t} \cdot B_{i g t q}, \forall i \in L W, g, t, q \\
P_{i g t q} \geq D_{i g t q}-e n t_{i g t} \cdot\left(1-B_{i g t q}\right), \forall i \in L W, g, t, q
\end{gathered}
$$

where $B_{i g t q}$ is a binary variable, equal to 1 when demand for a source $i$ in a region $g$ is lower than the supply. Further, the diverted or abstracted volumes should be within the limit of sustainable withdrawals, recommended by local governments (Eq.(14)).

$$
\sum_{q} P_{i g t q} \leq S P_{i g t}^{\max }, \forall i=L W, g, t
$$

where $S P_{i g t}^{\max }$ is the maximum sustainable water diversion or abstraction in a year $t$. These limits are in place to ensure the withdrawn volumes would not exhibit a detrimental impact on the environment.

\subsubsection{Reliability of water supply}

It is a common practice in many cities to be under agreed volumetric or temporal water restrictions, or an agreed reliability of supply. The reliability of water supply is calculated based on the volumetric shortage, when the demand exceeds supply. The water supply reliability, $W S R_{i g t q}$, is shown in Eq.15.

$$
W S R_{i g t q}=1-P D_{\text {igtq }} / \text { dem }_{\text {igtq }}, \forall i \in W, g, t, q
$$

where $P D_{i g t q}$ is the import in a period of water shortage and $d e m_{i g t q}$ is the urban water demand. The normalised reliability for the entire country is an average of the regional reliabilities (Eq. (16)).

$$
W R=\sum_{i \in W} \sum_{g} \sum_{t} \sum_{q} W S R_{i g t q} /\left(G^{\max } \cdot T^{\max } \cdot Q^{\max }\right)
$$

where $W R$ is the normalised reliability, $T^{\max }$ is the planning horizon period, $Q^{\max }$ - the number of seasons and $G^{\max }$ is the total number of regions.

\subsubsection{Capacity constraints}

At a given time $t$, every region $g$ and plant $p$ have production capacity, $T C A P_{g p t}$, which is a limiting factor for the plant feed flow, $V_{i g p t q}$. Therefore, the effluent should not exceed the total plant capacity, demonstrated in 
Eq.(17).

$$
\sum_{i \in S \cap S P_{p}} \sum_{i^{\prime} \in W} \varepsilon_{i i^{\prime}} \cdot V_{i g p t q} \leq T C A P_{g p t} / Q^{\max }, \forall g, p \in P G_{g}, t, q
$$

where $\varepsilon_{i i^{\prime}}$ is the production yield, depending on water source $i . P G_{g}$ is a subset of $g$ which contains the operating plant $p$ in region $g$, and $Q^{\max }$ is the number of seasons used to obtain seasonal capacity. Provided more water has to be processed to meet demand, the total capacity will increase by installing new plants or expanding old ones. A binary variable $I_{g p l t}$ is assigned for the installation of new plant $p$ with capacity $l$ in region $g$ at time $t$. When an increase in capacity is necessary, $I_{g p l t}$ is activated and equals 1 , otherwise it equals 0 . Another binary variable, $E_{g p l t}$, is assigned for the expansion of existing plants, which operates on the same principle.

$$
T C A P_{g p t}=T C A P_{g p, t-1}+\left.\sum_{l} i c a p_{p l} \cdot I_{g p l, t-i c t_{p}}\right|_{p \in N P}+\sum_{l} e c a p_{p l} \cdot E_{g p l, t-e c t_{p}}, \forall g, p \in P G_{g}, t
$$

where $i c t_{p}$ and $e c t_{p}$ are the respective construction and expansion times for plant $p, e c a p_{p l}$ represents the available options of capacity expansion $l$ and $i c a p_{p l}$ - the capacity installation options of new plants (NP) throughout the planning horizon.

At most one capacity level $l$ from a given number of options can be chosen (Eq. 19]).

$$
\sum_{l} \sum_{t} I_{g p l t} \leq 1, \forall g, p \in P G_{g} \cap N P
$$

$E_{g p l t}$ is a binary variable that is active when a plant is expanded which can happen up to $E^{\max }$ number of times (Eq. (20)).

$$
\sum_{l} \sum_{t} E_{g p l t} \leq E^{\max }, \forall g, p \in P G_{g}
$$

Only one capacity level $l$ from a given number of options can be chosen to be expanded at a time (Eq(21)).

$$
\sum_{l} E_{g p l t} \leq 1, \forall g, p \in P G_{g}, t
$$

Expansions can occur only after a plant has been installed, imposed by Eq.(22).

$$
\sum_{l} E_{g p l t} \leq \sum_{l} \sum_{t^{\prime} \leq t-i c t_{p}} I_{g p l t^{\prime}}, \forall g, p \in P G_{g} \cap N P, t
$$

The surface water that is kept in dams' storage should be less or equal than the current existing dams' capacity.

$$
D S_{i g t q} \leq D A M_{g t}, \forall i=" s w ", g, t, q
$$


In Eq. 23), $D A M_{g t}$ is the total capacity of dams in every region $g$ at time $t$. As $D S_{i g t q}$ is the water volume related to the ability to withdraw water from it, the volume of water which stagnates should be considered. Hence, simultaneously, the storage should not fall below the dead storage of the reservoir, expressed in Eq.(24).

$$
D S_{i g t q} \geq d s f \cdot D A M_{g t}, \forall i=" s w ", g, t, q
$$

where $d s f$ is a factor for the typical dead storage which remains in dams. The total dams capacity in a region equals the capacity of the existing dams and the newly built dams. The decision of building a new dam is executed through a binary variable $I D_{g l t}$.

$$
D A M_{g t}=D A M_{g, t-1}+\sum_{l} i d a m_{g l} \cdot I D_{g l, t-d c t}, \forall g, t
$$

where $d c t$ is the time for dam construction and $i_{d a m_{g l}}$ represents the option $l$ for capacity installation of dams in region $g$. Only one capacity option $l$ can be selected in a region $g$, given in Eq.(26).

$$
\sum_{l} \sum_{t} I D_{g l t} \leq 1, \forall g
$$

\subsubsection{Production constraints}

The water flows that are withdrawn to be processed in plants must equal the demand for raw sources, $D_{\text {igtq }}$, calculated from Eq. 272).

$$
D_{i g t q}=\sum_{p \in S P_{i} \cap P G_{g}} V_{i g p t q}, \forall i \in S, g, t, q
$$

The above equation applies only to raw sources, $S$, i.e. surface water, groundwater and seawater. The production of water for usage, $P_{i g t q}$, equals the summation of the effluents from plants treating different raw waters (Eq.(28)).

$$
P_{i g t q}=\sum_{i^{\prime} \in S} \sum_{p \in S P_{i^{\prime}} \cap P G_{g}} \varepsilon_{i^{\prime} i} \cdot V_{i^{\prime} g p t q}, \forall i \in W, g, t, q
$$

The regional user demand, $d e m_{i g t q}$, must be met and this condition is enforced from the equation below.

$$
\left(1-d f f_{g}\right) \cdot D_{i g t q}=\operatorname{dem}_{i g t q}, \forall i \in W, g, t, q
$$

where the equation applies only for final product water purpose $W$. The parameter $d f f_{g}$ accounts for the distribution losses due to broken pipes and leakages varying regionally. The recharge volumes, $R C_{i g t q}$, are estimated by the amount of water that has been collected in sewerage, treated by wastewater treatment plants and returned 
to surface and groundwater storages (Eq. (30)).

$$
R C_{i g t q}=\sum_{i^{\prime} \in W} u p \cdot \varepsilon_{i^{\prime} i} \cdot D_{i^{\prime} g t q}, \forall i \in L W, g, t, q
$$

253

\subsubsection{Operating expenditure constraints}

The operating expenditures are calculated in a similar manner. The operating costs for maintaining the dams, $O D A M_{t}$, are calculated by Eq.(34).

$$
O D A M_{t}=\sum_{g} \operatorname{vod}_{t} \cdot D A M_{g t}, \forall t
$$

where $\operatorname{vod}_{t}$ are the variable operating costs of dams at time $t$. The operating costs of plants consist of fixed, fop $_{\text {plt }}$ and variable, vop plt costs (Eq.(35)).

$$
O P L_{t}=\sum_{p \in O P} \sum_{l} f_{l} o p_{p l t}+\sum_{g} \sum_{p \in P G_{g} \cap N P} \sum_{l} f o p_{p l t} \cdot I P_{g p l t}+\sum_{g} \sum_{p \in P G_{g}} \sum_{l} \sum_{i: p \in S P_{i}} \sum_{i^{\prime} \in W} \sum_{q} v o p_{p l t} \cdot \varepsilon_{i i^{\prime}} \cdot V_{i g p t q}, \forall t
$$


The penalised cost for not meeting the product water demands is calculated by Eq. (36).

$$
\mathrm{OPen}_{t}=\sum_{i \in W} \sum_{g} \sum_{q} p c \cdot P D_{i g t q}, \forall t
$$

where $p c$ is a penalty cost rate, significantly higher than trading costs. The total OPEX is a summation of the operating dams' and plants' costs and trading costs, expressed from Eq. 37.

$$
O P E X_{t}=O D A M_{t}+O P L_{t}+O T R_{t}, \forall t
$$

\subsubsection{Objective function}

The total cost, $T C$, represents the addition of the capital, operating costs and penalty over the planning time horizon (Eq. (38)).

$$
\text { minimise } T C=\sum_{t}\left(c d f_{t} \cdot C A P E X_{t}+o d f_{t} \cdot O P E X_{t}+o d f_{t} \cdot O P e n_{t}\right)
$$

where $c d f_{t}$ and $o d f_{t}$ are discount factors of the capital and operating costs, respectively. The objective function is subject to:

- hydrological and supply-demand balances Eq.(3) - Eq.(7)

- procurement constraints Eq.(8) - Eq.(14)

- reliability constraints Eq.(15) - Eq.(16)

- capacity constraints Eq.(17) - Eq.(26)

- production constraints Eq. 27) - Eq.(30)

- capital expenditure constraints Eq. (31) - Eq. (33)

- operating expenditure constraints Eqs.(34), (35), Eq.(36) - Eq.(37)

In the light of the increasing importance of reliability, the objective is no longer to only minimise cost but also ensure the system is reliable to an economically adequate level while shortfalls are brought to minimum. Therefore, a multi-objective optimisation is applied next for the minimisation of the total cost and the maximisation of the reliability.

\subsection{Multi-objective optimisation formulation}

\subsection{1. $\varepsilon$-constraint method}

An $\varepsilon$ - constrained method is applied for the solution of the multi-objective optimisation where the first objective is to minimise the total cost for the supply chain and the second objective is to maximise the reliability. 
The reliability, however, is implicitly related to the penalty, $O P e n_{t}$, which is the reason it has to be excluded from the objective function of the total cost. Hence,

$$
\text { Objective } 1: \text { minimise } T C=\sum_{t}\left(c d f_{t} \cdot C A P E X_{t}+o d f_{t} \cdot O P E X_{t}\right)
$$

which is subject to:

$$
\text { Objective 2: } \quad W R \geq W R^{*}
$$

and

- hydrological and supply-demand balances Eq.(3) - Eq.(7)

- procurement constraints Eq.(8) - Eq. (14)

- reliability constraints Eq.(15) - Eq.(16)

- capacity constraints Eq.(17) - Eq.(26)

- production constraints Eq. (27) - Eq.(30)

- capital expenditure constraints Eq.(31) - Eq.(33)

- operating expenditure constraints Eqs. (34), (35), Eq. (37)

The obtained solutions will be Pareto optimal and any of them can be chosen to plan the water supply chain. The Nash bargaining approach, however, can provide the exact point on the Pareto curve where the two strategies can co-exist at equilibrium.

\subsubsection{Nash bargaining approach}

A cooperative game is considered to obtain the best strategies for expenditures and supply reliability using Nash bargaining approach. It is aimed to minimise total country's cost by increasing the difference between the status quo point and the optimisation variable. On the other hand, it is aimed to maximise the reliability by increasing the difference between the variable and its status quo point. By maximising the product of all the strategies' deviations, a fair solution distribution is ensured where no strategy can be improved. The dependency is expressed in $\mathrm{Eq}(41)$.

$$
\text { maximise } \quad \bar{\tau}=\left(W R-W R^{q u o}\right) \cdot\left(T C^{q u o}-T C\right)
$$

where $T C^{q u o}$ is the upper cost bound for the country, which is obtained in a case no infrastructure is planned and no trading occurs. Then, $T C \leq T C^{q u o}$. $W R_{\text {quo }}$ is the corresponding point for the status quo pair. Then, $W R \geq$ $W R^{q u o}$. Eq.(41) results in a non-linear formulation which can result in local optima. Therefore, it follows to be further linearised. Eq. (41) is expressed as a separable function by taking the logarithm of both hand sides and 
using logarithmic properties:

$$
\ln \bar{\tau}=\ln \left(W R-W R^{q u o}\right)+\ln \left(T C^{q u o}-T C\right)
$$

Each of the logarithmic terms on the right hand side of the equation contains a continuous variable, which means they are still non-linear. Hence, the total cost, $T C$, and water reliability, $W R$, domains are discretised into $k$ number of points, which necessitates the introduction of the $T C_{k}$ and $W R_{k}$ parameters. An additional parameter, $\xi_{k}$ is introduced to equal the logarithm of the cost difference (Eq. (43)).

$$
\xi_{k}=\ln \left(T C^{q u o}-T C_{k}\right), \forall k
$$

Similarly, a parameter, $\lambda_{k}$ is assigned for the logarithm reliability difference, shown in Eq.(44).

$$
\lambda_{k}=\ln \left(W R_{k}-W R^{q u o}\right), \forall k
$$

An SOS type 2 variable, $X_{k}$, is used to represent the selection of the cost, shown below:

$$
\sum_{k} T C_{k} \cdot X_{k}=\sum_{t}\left(c d f_{t} \cdot C A P E X_{t}+o d f_{t} \cdot O P E X_{t}\right)
$$

The same variable is used for the reliability, expressed below:

$$
\sum_{k} W R_{k} \cdot X_{k}=\sum_{i \in W} \sum_{g} \sum_{t} \sum_{q} W S R_{i g t q} /\left(G^{\max } \cdot T^{\max } \cdot Q^{\max }\right)
$$

Up to two consecutive $\mathrm{k}$ points can be selected through a special set order set (SOS2) requirement. The active option $k$ should add up to 1 , represented in Eq.(47).

$$
\sum_{k} X_{k}=1
$$

And the auxiliary variable has to be positive.

$$
X_{k} \geq 0, \forall k
$$

Then, the objective function becomes:

$$
\text { maximise } \quad \hat{\tau}=\sum_{k}\left[\left(\xi_{k}+\lambda_{k}\right) \cdot X_{k}\right]
$$

which is subject to: 
- hydrological and supply-demand balances Eq.(3) - Eq.(7)

- procurement constraints Eq.(8) - Eq.(14)

- reliability constraints Eq.(15)

- capacity constraints Eq.(17) - Eq.(26)

- production constraints Eq. 27) - Eq. (30)

- capital expenditure constraints Eq.(31) - Eq.(33)

- operating expenditure constraints Eqs.(34),(35), Eq.(37)

- game theory constraints Eq. (45) - Eq.(49)

The applicability of the mathematical model is investigated through a case study, presented in the following section.

\section{Illustrative example}

The applicability of the proposed framework is investigated through the implementation of a case study based on Australia. The objective is to minimise the total country's cost for obtaining an optimal water network by meeting the regional urban water demands. In this section, the major data on regional divisions, water demands, efficiency factors, hydrological data, installation and expansion capacities, and cost factors are presented.

\subsection{Geographical representation of Australian regions}

Australia is divided into 8 internal state and territory governments, namely: Queensland (QLD), New South Wales (NSW), Victoria (VIC), South Australia (SA), Western Australia (WA), Northern Territory (NT), Australian Capital Territory (ACT) and Tasmania (TAS). Each state has its local state government which owns all or most of the water providers operating within the state [Australian Government, 2017]. Australian water providers can supply urban and rural areas with drinking as well as different quality grades water. Due to the large number of providers and the available data on regional water demand and hydrological balances, the spatial discretisation is performed on a state basis. Besides water supply, majority of the suppliers offer sewerage management, too. A map showing the considered regions is shown in Fig. 5 .

\subsection{Existing plants and dams for providing urban water supply}

Each state possesses assets for the treatment of any of the three sources considered: seawater, surface water and groundwater. 


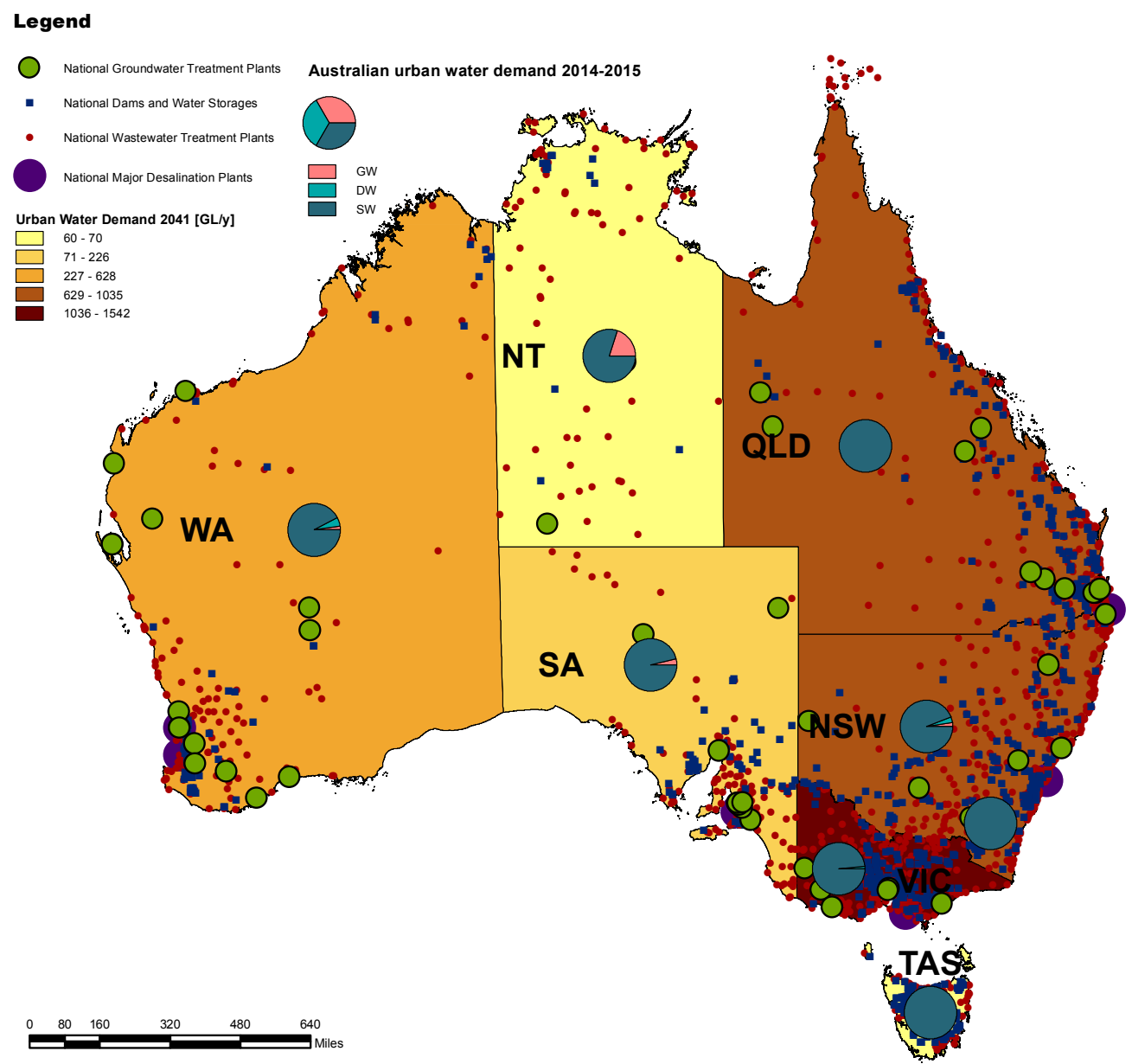

Figure 5: Dams, major plants and urban water demand and source mix in Australia

The prolonged lack of rainfall from 2000 - 2010 in Australia necessitated finding alternative sources of water supply. Seawater desalination, although an expensive option, has been considered as the leading solution to water shortages. Currently, in every state but TAS, NT and ACT exists at least one large capacity seawater desalination plant (Fig. 5). Their locations, capacities and construction costs are summarised in Table 1 . The plants are in

Table 1: Seawater desalination plants, locations, capacities and cost

\begin{tabular}{lccc}
\hline Name & State & $\begin{array}{c}\text { Max capacity } \\
{[\text { ML/d] }}\end{array}$ & $\begin{array}{c}\text { Construction cost } \\
\text { [M USD] }\end{array}$ \\
\hline Gold Coast Desalination Plant & Queensland & 167 & 912 \\
Perth Desalination Plant & Western Australia & 130 & 294 \\
Kurnell Desalination Plant & New South Wales & 500 & 1,444 \\
Southern Seawater Desalination Plant & Western Australia & 290 & 726 \\
Victorian Desalination Plant & Victoria & 550 & 2,660 \\
Port Stanvac Desalination Plant & South Australia & 270 & 1,391 \\
\hline source: Australian Government & 2016b & &
\end{tabular}

source: Australian Government 2016b

operation as a non-conventional measure in drought periods, when there is insufficient freshwater in the states' 
storages. In 2016 all desalination sites were producing drinking water.

Groundwater in Australia is extracted from underground aquifers and after the appropriate treatment it can be used for water supply, agriculture and industry. Its salinity can be high enough to be considered for brackish water and hence, its purification can sometimes be referred to as brackish water desalination. States that count on groundwater availability are Western Australia and the Northern Territory due to their remoteness from the main river basin - Murry - Darling. Fig. 5 depicts the locations of the larger groundwater treatment plants in Australia.

Dams can be defined as "an artificial barrier that has the ability to impound water, wastewater, or any liquidborne material, for the purpose of storage or control of water" International Commission on Large Dams, 2016]. They can vary immensely in size and shape, from small dams that serve for watering farms to large dams that can provide the storage for urban centres. In Australia there are altogether more than 600 dams numbering a total capacity of approximately $80,000 \mathrm{GL}$. A spatial representation of all Australian dams' locations is shown in Fig. 5. The cumulative capacity of all dams in a state is reported in Table 2.

Table 2: Demand - supply regional data

\begin{tabular}{lccc}
\hline & $\begin{array}{c}\text { Accumulative dams' capacity } \\
{[\mathrm{GL}]}\end{array}$ & $\begin{array}{c}\text { Urban water consumption per capita } \\
{[\mathrm{kl} / \text { year] }}\end{array}$ & $\begin{array}{c}\text { Distribution losses } \\
{[\%]}\end{array}$ \\
\hline SA & 2,257 & 125 & 11.9 \\
VIC & 12,864 & 188 & 7.9 \\
NSW & 21,352 & 104 & 11.1 \\
QLD & 10,429 & 123 & 12.0 \\
ACT & 158 & 102 & 7.2 \\
NT & 285 & 211 & 19.5 \\
WA & 11,474 & 136 & 22.0 \\
TAS & 22,141 & 112 & 36.4 \\
\hline \multicolumn{2}{r}{ source: } & Australian Bureau of Statistics [2015a b]
\end{tabular}

Surface water in Australia is diverted from lakes, rivers and streams and dams, and its abstraction volumes depend on the precipitation in the territories. Tasmania possesses sufficient amounts of freshwater whereas SA, VIC, QLD and NSW rely predominantly on the availability in Murry - Darling Basin (MDB). The availability of freshwater in WA and NT is limited. Surface water treatment plants may involve full treatment with coagulation and filtration or membrane purification, or only chlorination or UV disinfection. In the former case, the facilities have maximum capacity while in the latter one, the reservoirs capability to supply water is considered.

\subsection{Urban water sources and demands}

In Fig. 5 the percentage of the different water source origins per state used for urban water supply in 20142015 are shown. It can be deduced from the figure that the eastern territories rely mostly on surface water due to the presence of Murray Darling Basin (MDB) while the territories to the west and north provide their urban water by treating groundwater from aquifers and desalinating seawater Australian Bureau of Statistics, 2015b. 
The desalination plants in QLD, VIC and NSW were on a stand-by mode for the period. Additional source originrelated assumptions in this work include: (i) self-supplied and reuse water are not accounted for, and (ii) surface water treatment, and groundwater and seawater desalination provide the majority of the urban water supply.

The consumption of urban water comes from residential, commercial, municipal and industrial water usage [Planning Institute Australia 2016]. Its projections heavily depend on population growth, climate change, type of houses, economic growth, water efficient appliances, demographics, etc. The total urban water resources predictions are calculated by multiplying the projected population by the consumption per capita, which, on the other hand, is a quotient of the urban water demand and population in the base year of calculation (2014). The regional consumption per capita is given in Table 2. It is assumed the consumption rate does not alter from the patterns observed in 2014 Australian Bureau of Statistics, 2015a. Population projections follow three scenarios: a high, medium and low one. The medium scenario is seen as the most probable course and therefore, the scenario used as a prediction in the case study. Interpolation was used to determine the population between 2026 and 2030 for Western Australia. The derived urban water demand predictions are illustrated in Fig. 6.

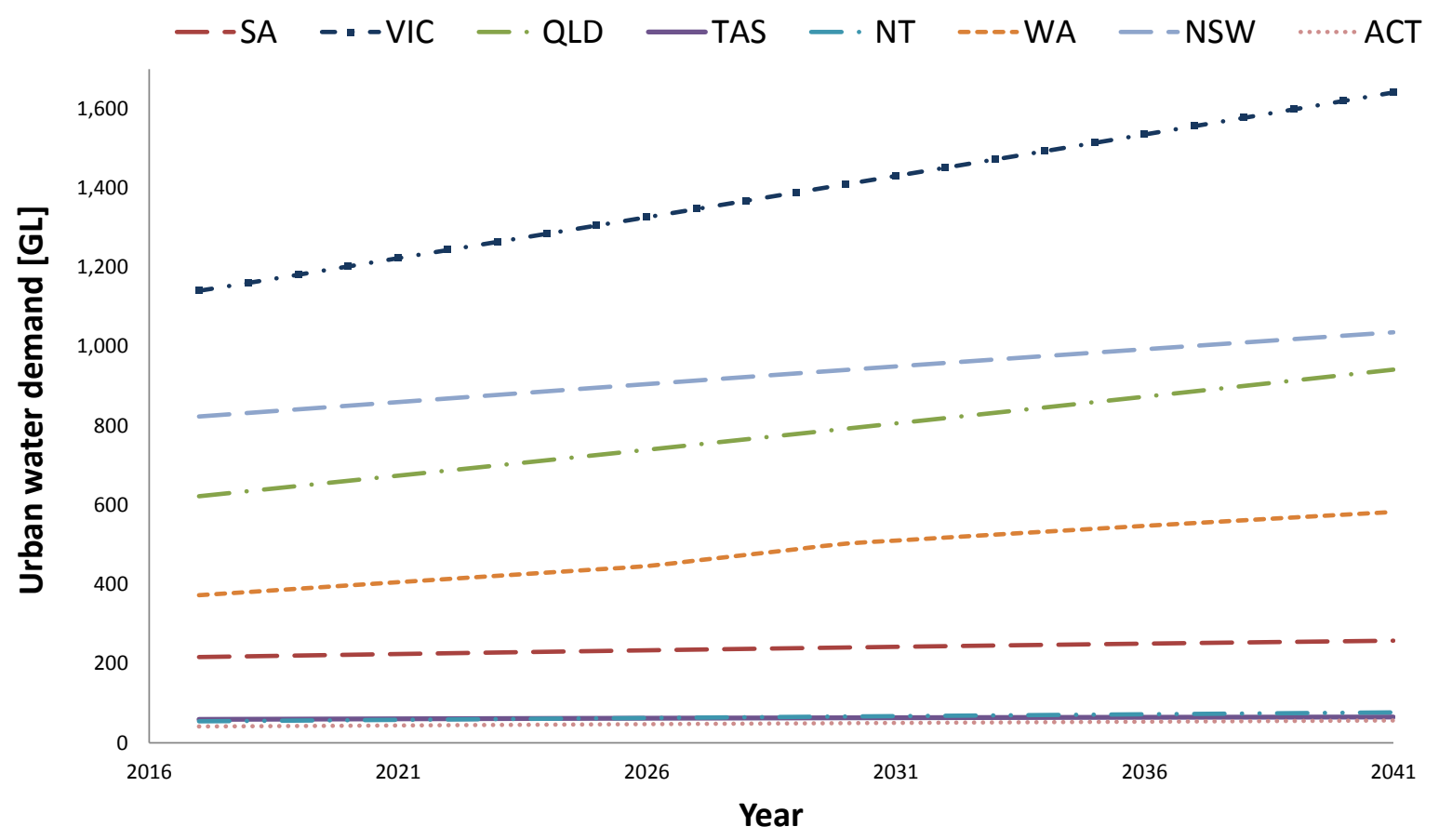

Figure 6: Predicted urban water demand from 2016 to 2041

The population projections for Victoria and Queensland indicate approximately a $47 \%$ and $56 \%$ respective increase and consequently, affecting the predicted water consumptions in those states with the same estimated percentage. Almost insignificant change in the predicted consumption in ACT, SA, TAS and NT is seen as a relatively steady population expected for that period. The highest consumption at the end of the planning horizon 
would be in VIC, where the demand will reach approximately $1,550 \mathrm{GL}$ in year 2041 .

The seasonal variation in demand is also considered where water consumption in summer is approximately twice as much as consumption in winter, whereas spring and autumn are characterised with moderate demands. The assumption follows the outcome of studies for urban water use varying with seasonal rainfall and temperatures Maidment et al. 1985].

A high percentage from the urban water, which has been distributed, is lost due to leakages, broken pipes, etc. The percentage varies for different states as shown in Table 2 [Australian Bureau of Statistics, 2015b].

\subsection{Hydrological data}

Climate in Australia varies from year-to-year due to the shifting and alternating extensive dry and wet patterns in the Pacific Ocean. The phenomena refer to El Niño and La Niña and cause prolonged droughts occurring pvery three to eight years followed by prolonged rainfalls occurring with the same frequency Australian Bureau of Meteorology, 2008. Consequently, hydrological components, which determine the availability of water, are affected. The water cycle, or budget, is a balance of the inflows, outflows and changes in storage within a geographic area, or catchment. In this case study, the inflows, which are given as data, are rainfalls, run-off and streamflows, and the outflow, given as data, is evaporation.

Regional seasonal changes in the rainfall and pan evaporation are considered, where depicted in Fig. 7 and Fig. 8 are the total values for Australia for the period 2016-2041. The data are the recorded historical data per state which is available from the Australian Bureau of Meteorology Australian Bureau of Meteorology. 2016ba]. Pan evaporation is the evaporation that occurs in a pan and therefore, has to be corrected with a correction factor which can range between 0.47 and 1.18 [Finch and Calver, 2008. A value of 0.75 is adopted in this case study. Australian summer takes place in months January - March, autumn in April - June, winter in July - September and spring in October - December. The largest numbers for precipitation and evaporation are recorded in autumn and winter while both decrease in the spring and summer seasons. 


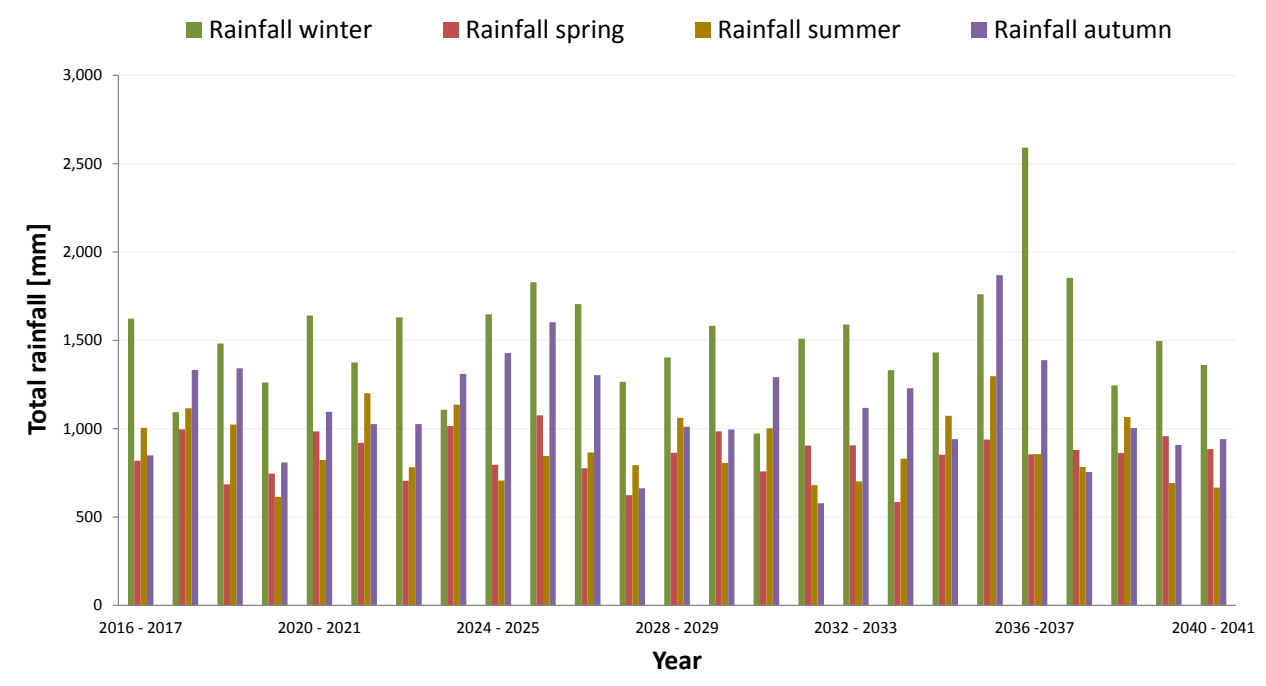

Figure 7: Total seasonal rainfall in the period 2016 - 2041

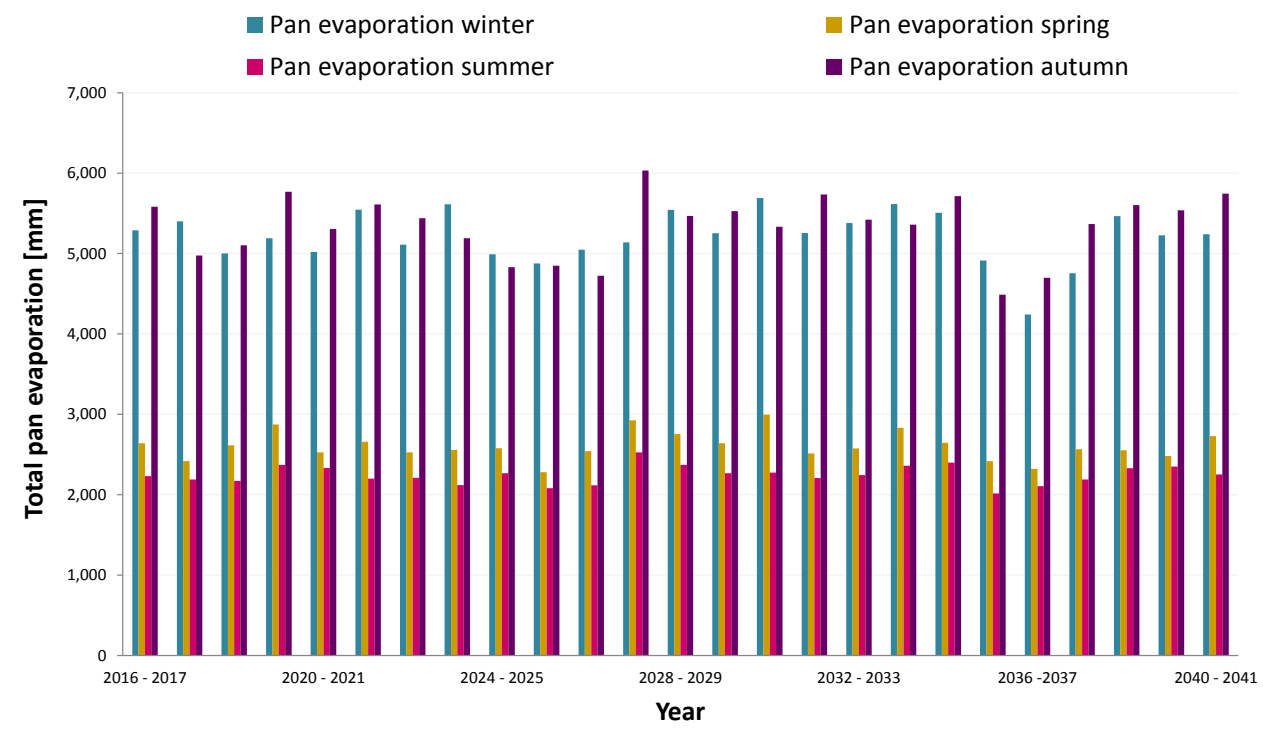

Figure 8: Total seasonal pan evaporations in the period 2016 - 2041

Run-off is taken from personal correspondence with the Australian Bureau of Meteorology. Infiltration is the recharge inflow to groundwater and is a fraction of the rainfall. A worst-case scenario of $10 \%$ recharging aquifers is assumed [American Planning Association 2006].

The streamflows data have been collected from the official site of the Australian Bureau of Meteorology Australian Bureau of Meteorology [2016c] where all the major rivers gauged historical flowrates were recorded. The flows from different river systems were added up. It can be observed from Fig. 9 that the volumes of the streams follow rainfall trends. The data is processed per region but the total streamflows in a given period are depicted in the figure.

The initial storages of surface and groundwater are reported in Table 3 Surface water storages are divided 


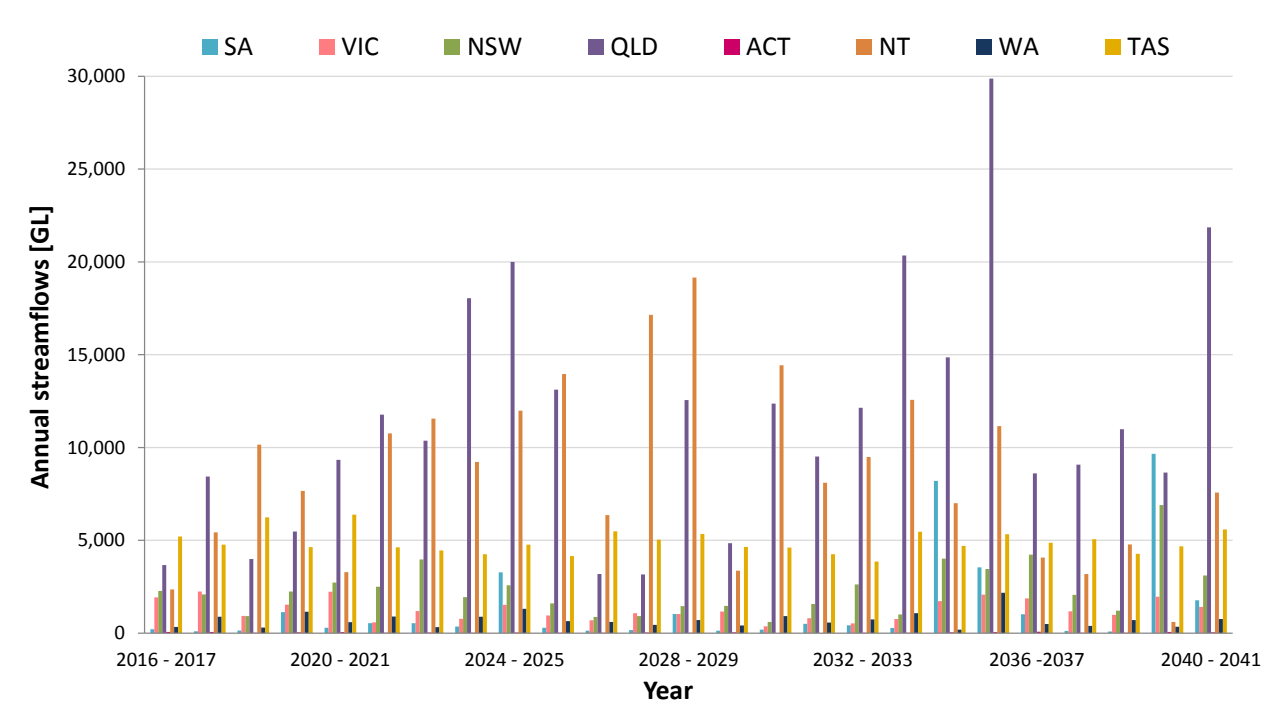

Figure 9: Total seasonal streamflows in the period 2016 - 2041

Table 3: Initial regional storage volumes

\begin{tabular}{lccc}
\hline State & $\begin{array}{c}\text { Initial natural surface water storage } \\
{[\mathrm{GL}]}\end{array}$ & $\begin{array}{c}\text { Initial } \\
\text { natural groundwater storage } \\
{[\mathrm{GL}]}\end{array}$ & $\begin{array}{c}\text { Initial reservoir storage } \\
{[\mathrm{GL}]}\end{array}$ \\
\hline SA & 5,321 & $15,031,350$ & 2,223 \\
VIC & 9,040 & $1,840,000$ & 9,963 \\
NSW & 9,040 & $5,257,000$ & 15,880 \\
QLD & 7,030 & $45,500,000$ & 7,383 \\
ACT & 2,061 & 23,000 & 147 \\
NT & 7,480 & 8,647 & 223 \\
WA & 368 & $46,458,150$ & 7,624 \\
TAS & 12,207 & $16,000,000$ & 12,207
\end{tabular}

source: Australian Bureau of Meteorology [2017], Australian Government [2016c], Lew |Vaillant [2015], Murray-Darling Basin Commission 1999], Department of Natural Resources, Environment, the Arts and Sport 2009.

into natural reservoirs and dams while groundwater storages appear only in their natural form, i.e. in aquifers. It must be noted that the groundwater storages are based on estimations.

\subsection{Water rights and markets in Australia}

Water markets in Australia have gone a long way from their emergence in 1980s, through their expansion in 1990 s and early 2000 , to the transition to sustainable water markets since 2007. Although Australian water market is increasingly mature, it can still benefit from further reforms to improve efficiency and the availability of information for decision-making of market participants. The largest trading activities occur in the MDB. In particular, interstate trade is possible in the southern connected basin between the various trading zones in NSW, ACT, VIC and SA, as well as between NSW and QLD in the northern parts of the basin. The allowed trading neighbourhoods in this case study are the neighbouring where trading activities exist or where they can potentially exist. The available resources around Brisbane and Sydney are assumed not to be participating in the trading. Instead the states' capitals water demand is met through their desalination plants and existing water treatment 
plants in proximity. Surface water and groundwater are allowed to trade.

In this work, the national Australian equivalent terms of "allocation" and "entitlement" are used, where "allocation" is defined as "the specific volume of water allocated to water access entitlements in a given water year or allocated as specified within a water resource plan" and "entitlement" is defined as "exclusive access to a share of water from a specified consumptive pool as defined in the relevant water plan" Australian Bureau of Meteorology 2016d. Allocation trade involves transferring a volume of water allocation from a seller to a buyer. Allocation trade is allowed when its volume is equal or lower than the amount of unused allocated water of the seller [Victorian Water Register, 2017].

Table 4: Regulated entitlements per state and rural water supply

\begin{tabular}{|c|c|c|c|}
\hline State & $\begin{array}{c}\text { surface water entitlements } \\
{[\mathrm{GL}]}\end{array}$ & $\begin{array}{l}\text { groundwater entitlements } \\
\text { [GL] }\end{array}$ & $\begin{array}{c}\text { rural water consumption } \\
{[\mathrm{GL}]}\end{array}$ \\
\hline SA & 844 & 530 & 161.7 \\
\hline VIC & 4,729 & 870 & $1,874.0$ \\
\hline NSW & 9,940 & 1,154 & $3,160.3$ \\
\hline QLD & 4,705 & 899 & $1,541.6$ \\
\hline ACT & 75 & 1 & 0 \\
\hline NT & 132 & 126 & 0 \\
\hline WA & 946 & 1,491 & 167.6 \\
\hline TAS & 1,650 & 0 & 33.3 \\
\hline
\end{tabular}

The entitlements reported in Table 4 are the rights to withdraw water from surface and groundwater sources. The Tasmanian licences largely consist of unregulated surface water entitlements. Because of the year-round availability of water in Tasmanian rivers, complemented by releases from the hydro-electricity generation scheme, flow volumes largely exceed urban and irrigation demand. As the entitlements are given for both, urban and rural water consumption, the latter is taken into account under the assumption it will change insignificantly within the planning horizon. Hence, there has been no need to issue entitlements that could be limited by allocation announcements. Entitlements are allocated on 1st July every year which is considered the beginning of the water market year. Therefore, the start and end of the time periods are adjusted to match the water market year in Australia. It is worth mentioning that Australia does not import water from abroad. It is assumed that the entitlements remain steady throughout the planning horizon and that carry-overs are possible for all states. It must be noted that there is a maximum volume that can ensure sustainable abstraction. Surface water withdrawals are also constrained by a maximum yield (Table 5).

Two major grades of water depending on their reliability exist, i.e. high and low. However, the prices are expressed in volume weighted average price. This is the agreed price among entities exclusive of transaction costs. Prices of allocation trades are determined by the value placed on water by buyers and sellers in response to factors such as purpose of water use, weather patterns, available allocations, jurisdictional arrangements, etc. The trading prices in each state are determined following a number of assumptions: (i) the prices have been 
Table 5: Maximum regional sustainable withdrawal limits

\begin{tabular}{lcc}
\hline State & $\begin{array}{c}\text { surface water sustainable abstraction limits } \\
{[\mathrm{GL}]}\end{array}$ & $\begin{array}{c}\text { groundwater sustainable diversion limits } \\
{[\mathrm{GL}]}\end{array}$ \\
\hline SA & 750.8 & $1,979.2$ \\
VIC & $6,326.2$ & $3,355.5$ \\
NSW & $6,010.0$ & $5,914.4$ \\
QLD & $3,244.0$ & $2,693.1$ \\
ACT & 18.0 & 17.7 \\
NT & 54.4 & $5,476.4$ \\
WA & 856.8 & $7,223.5$ \\
TAS & $3,542.7$ & $2,530.8$ \\
\hline \multicolumn{2}{c|}{ source: Harrington and Cook } &
\end{tabular}

derived using historical data which have been extrapolated; (ii) the price is mostly affected by the rainfall rather than water demand. Reliable recording of groundwater temporary trading exists, for instance, only in two cases in WA: 51 USD/ML and 165 USD/ML [Legislative Assembly Committee, 2000]. These prices are similar and in the range of surface water trading prices and therefore, taken as values for groundwater allocation trading prices. Inter-state transfers have trading price that includes applicable transaction costs or the so called gross transfer price. The transaction cost, which is charged by the selling state, is based on percentages from the total trade cost, reported by The Allen Consulting Group [2006]. These percentages for each state are NSW - 3.1\%, VIC $2.7 \%$, SA - 21\%. Further, it is assumed QLD, NT and WA charge 3.5\% from the trade price.

\subsection{Operating and capital costs}

Three options for installation and expansion capacities of each plant type are provided and reported in Table 6 The respective capital costs are estimated from correlations obtained from data observations and from economies of scale expressions [Independent Pricing and Regulatory Tribunal, 2011]. For the capital and operating costs it is considered the seawater desalination plants operate with high salinity rejection reverse osmosis membranes while the groundwater treatment plants utilise brackish water reverse osmosis membranes as desalination technologies. A conversion rate of $1 \mathrm{AUD}=0.754 \mathrm{USD}$ is adopted $\mathrm{XE}$, 2016].

Table 6: Capacities for plants installation, expansion and respective costs per state

\begin{tabular}{|c|c|c|c|c|c|c|}
\hline \multirow[t]{2}{*}{ Plants type } & \multicolumn{2}{|c|}{ Installation } & \multicolumn{2}{|c|}{ Expansion } & \multicolumn{2}{|c|}{ Operating costs } \\
\hline & $\begin{array}{c}\text { Capacity } \\
{[\mathrm{ML} / \mathrm{y}]}\end{array}$ & $\begin{array}{c}\text { Capital cost } \\
\text { [M USD] }\end{array}$ & $\begin{array}{c}\text { Capacity } \\
{[\mathrm{ML} / \mathrm{y}]}\end{array}$ & $\begin{array}{c}\text { Capital cost } \\
\text { [M USD] }\end{array}$ & $\begin{array}{c}\text { Fixed } \\
{[U S D / M L]}\end{array}$ & $\begin{array}{r}\text { Variable } \\
\text { [USD/ML] }\end{array}$ \\
\hline \multirow{3}{*}{ Surface water treatment plants } & 50,000 & 52.32 & 10,000 & 10.75 & 528.6 & 1,233 \\
\hline & 100,000 & 84.67 & 25,000 & 24.53 & 528.6 & 1,233 \\
\hline & 200,000 & 149.38 & 50,000 & 45.78 & 528.6 & 1,233 \\
\hline \multirow{3}{*}{ Groundwater treatment plants } & 20,000 & 191.74 & 10,000 & 43.94 & 585.9 & 1,367 \\
\hline & 50,000 & 479.35 & 25,000 & 100.23 & 585.9 & 1,367 \\
\hline & 100,000 & 958.70 & 50,000 & 187.04 & 585.9 & 1,367 \\
\hline \multirow{3}{*}{ Seawater desalination } & 50,000 & 970.00 & 50,000 & 456.18 & 2,000 & 1,386 \\
\hline & 100,000 & $1,943.60$ & 100,000 & 851.27 & 2,000 & 1,386 \\
\hline & 150,000 & $2,916.60$ & 150,000 & 1,226 & 2,000 & 1,386 \\
\hline
\end{tabular}

It is assumed it takes two years to build a surface water treatment or groundwater treatment plants, and four 
years to install a seawater desalination plant. It is also assumed that an expansion of any plant and building a dam take a year. Only installation of total dams capacity per state is considered. Table 7 shows the options

Table 7: Capacities for dams installation and respective costs per state

\begin{tabular}{|c|c|c|c|c|c|}
\hline State & $\begin{array}{r}\text { Capacity } \\
\text { [GL] }\end{array}$ & $\begin{array}{r}\text { Capital cost } \\
{[\mathrm{M} \text { USD] }}\end{array}$ & State & $\begin{array}{r}\text { Capacity } \\
\text { [GL] }\end{array}$ & $\begin{array}{c}\text { Capital cost } \\
\text { [M USD] }\end{array}$ \\
\hline \multirow{3}{*}{$\mathrm{SA}, \mathrm{ACT}$} & 1,000 & 756 & \multirow{3}{*}{ NT } & 500 & 378 \\
\hline & 2,000 & 1,512 & & 1,000 & 756 \\
\hline & 3,000 & 2,268 & & 2,000 & 1,512 \\
\hline \multirow{3}{*}{ VIC, QLD, WA, TAS } & 5,000 & 3,780 & \multirow{3}{*}{ NSW } & 10,000 & 7,560 \\
\hline & 10,000 & 7,560 & & 20,000 & 15,120 \\
\hline & 15,000 & 11,340 & & 30,000 & 22,680 \\
\hline
\end{tabular}

450

of capacities and their respective costs. The operating costs for dams are assumed to be $120 U S D / M L$ State Government Victoria 2011].

The capital and operating discount factors are calculated using a discount rate of $6 \%$, which is commonly used in water and wastewater treatment, desalination and water sanitation [Souza et al. 2011. Whittington et al. 2008.

\section{Results and discussion}

In this section are the computational results and performance of the single and multi-objective solution approaches presented in Section 3 and applied to the case study described in Section 4 are discussed. The MILP models are implemented in GAMS 24.7.1, using solver CPLEX 12.6.1, on a PC with Intel Core $i 7-3770$ CPU $3.40 \mathrm{GHz}$, RAM $16 \mathrm{~GB}$. The relative optimal gap has been set to $0.01 \%$ for the monolithic approach and $0.1 \%$ for the multi-objective approaches.

\subsection{Monolithic approach}

The model is comprised of 78,529 equations, 70,177 continuous and 19,550 discrete variables. The solution is returned within 823 seconds with an objective function of 327.94 bnUSD. A breakdown of the total cost is given in Table 8, alongside with total regional costs. Forty two water treatment plants are expanded and one new plant

Table 8: Discounted cost components and regional costs of the optimal water management design

\begin{tabular}{|c|c|c|c|}
\hline Cost component & [bnUSD] & State & Regional cost [bnUSD] \\
\hline Capital expenditure of installed/expanded plants and dams & 2.33 & SA & 14.49 \\
\hline Operating expenditure of plants and dams & 320.82 & VIC & 87.18 \\
\hline \multirow[t]{6}{*}{ Penalties for unmet demand } & 4.79 & NSW & 80.75 \\
\hline & & QLD & 51.99 \\
\hline & & ACT & 2.90 \\
\hline & & NT & 3.99 \\
\hline & & WA & 48.37 \\
\hline & & TAS & 38.27 \\
\hline Total cost & 327.94 & & 327.94 \\
\hline
\end{tabular}


is built in the light of the increasing 25-year period demand, which is reflected in the capital cost expenditure, shown in Table 8. The ongoing costs for operating water services account for approximately $95 \%$ of the total cost. In OECD [2009], the Australian gross domestic product of total water and wastewater services per year have been reported with average annual expenditures of 6.86 bnUSD by 2015 and projected average annual expenditures of 9.95 bnUSD by 2025. Extrapolating the latter estimate for the period 2016-2040, results in approximately 249 bnUSD without expenditure increase and 311 bnUSD with 3 bnUSD increase every 10 years for the total expenditure. Consequently, the solution returned is in the same order of magnitude as the projected costs and roughly $6 \%$ off from the second estimation. The occurring difference can be caused by a number of assumptions. Firstly, the reported values in the report by OECD [2009] are average values for provision and maintenance of adequate water infrastructure. Secondly, the expenditure increase assumed is linear which may not be the case in reality. Additionally, the report does not specify the targeted reliability of future infrastructure while optimisation model returns the highest possible reliability which is geq $99 \%$. Finally, not accounting for self-supply in the model does not lower the demand hence, decisions for larger and more capacity expansions and build out are made.

The regional costs are reported in Table 8, from where it can be observed the highest costs, 87.18 bnUSD, 80.75 bnUSD and 51.99 bnUSD, incur in VIC, NSW and QLD, respectively. Those areas are densely populated and projections shown in Fig. 6 manifest a substantial water demand belongs to them, which can explain the difference in total cost in comparison with the rest of the states. The penalty is triggered in 2016-2017 in VIC, QLD, NSW, NT and WA due to the capacity shortage to produce clean water.

In the same year the groundwater abstractions are on average 4 times higher than the annual abstractions for the rest of the periods and the seawater diversions are almost twice as high as the annual intakes towards 20402041 (Fig. 10). In the figure, it is observed the groundwater abstraction rises steadily, reaching $77 \mathrm{GL} /$ year, while seawater intake increases exponentially to approximately $131 \mathrm{GL} /$ year towards the end of the planning horizon. Although seawater desalination is available, it is not an economically viable option until demand cannot longer be met by conventional water resources. Surface water procurement remains the major source of water provision, and grows steadily for 25 years, starting at 2,534 GL in the first period and ending at 4,972 GL in the last period. This is under the assumption that the total precipitation will remain the same as precipitation in the last 25 years. Diversifying the water source mix is associated with the yearly gradual operating costs increment from 21.4 to 28.8 bnUSD. 


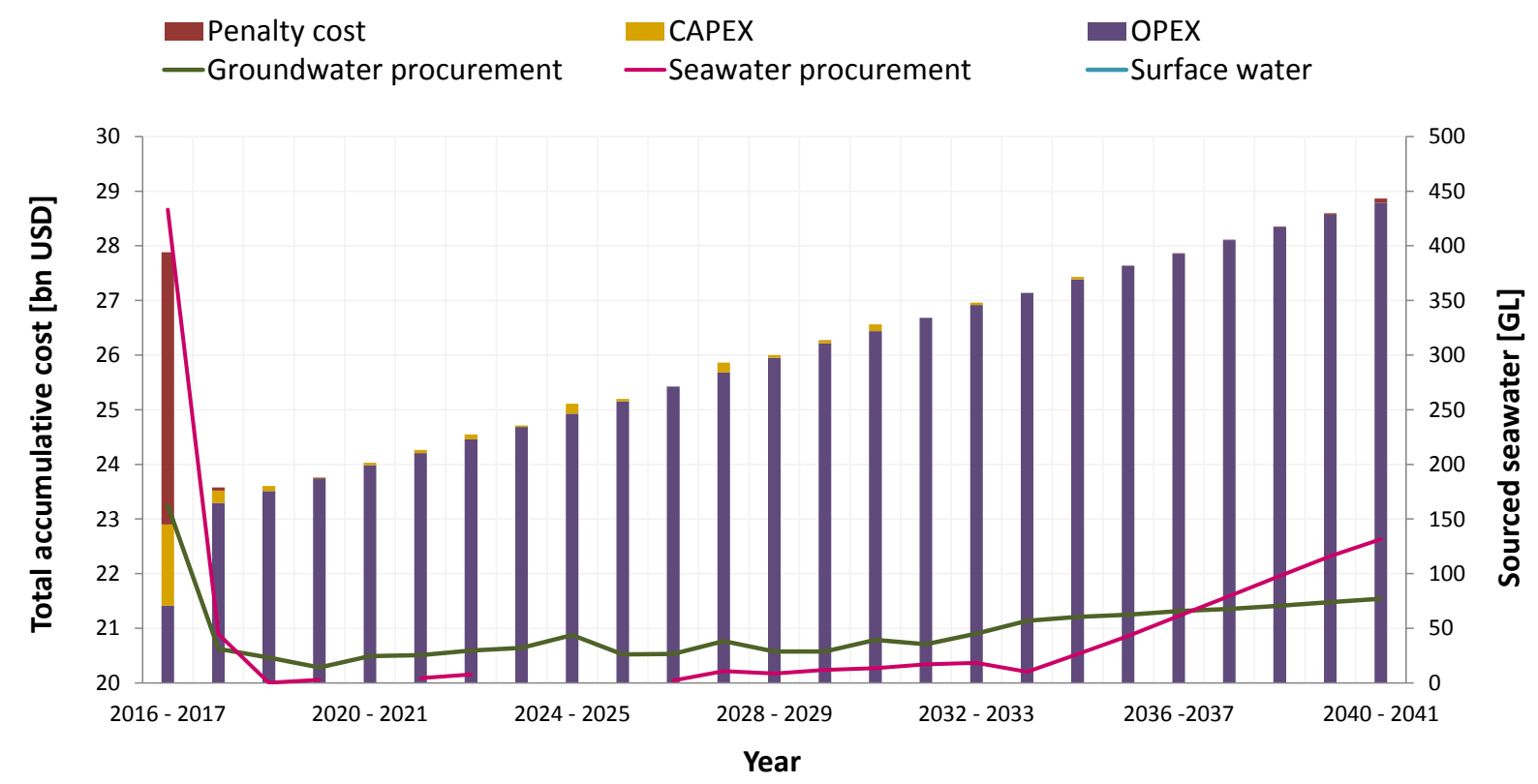

Figure 10: Components costs and resources intakes in the period $2016-2041$

Fig. 11 illustrates the total regional plant capacity in the period 2016-2041. The highest step-changes are made by QLD from approximately $717 \mathrm{GL} / y$ to almost $1,342 \mathrm{GL} / \mathrm{y}$, by $\mathrm{VIC}$ from $1,043 \mathrm{GL} / y$ to $2,343 \mathrm{GL} / \mathrm{y}$, and by WA from $508 \mathrm{GL} / y$ to $1,158 \mathrm{GL} / \mathrm{y}$ production capacities. The three states which have the largest total costs also possess the largest production capacities, followed by WA. Although NSW necessitates $375 \mathrm{GL} / \mathrm{y}$ of extra capacity for the entire planning horizon, the operation of its already existing facilities contributes to its cost. In 2040-2041, the water demand for QLD, VIC and WA is estimated at, respectively, $960 \mathrm{GL}, 1675 \mathrm{GL}$ and $805 \mathrm{GL}$, including distribution losses. The plants' utilisation in the three states is kept at or above $70 \%$ at the last year of the planning span. ACT and NT necessitate two expansions each, of $20 \mathrm{GL} / \mathrm{y}$ total additional capacity in the former state, and $35 \mathrm{GL} / \mathrm{y}$ in the latter. SA possess enough plant capacity to be able to meet its increasing demand therefore, no installations or expansions are needed in the state. Its plants operate at $45 \%$ of their capacities in 2016-2017, and at 54\% of their capacities in 2040-2041. It must be noted that maximum two expansions per plant have been allowed, which are preferred over installations of new plants due to their lower cost and shorter building period. The options for capacities have been provided taking into account real capacities of each plant type, translating into the smaller and more frequent selection of capacities expansions, as seen in Fig. 11 . 


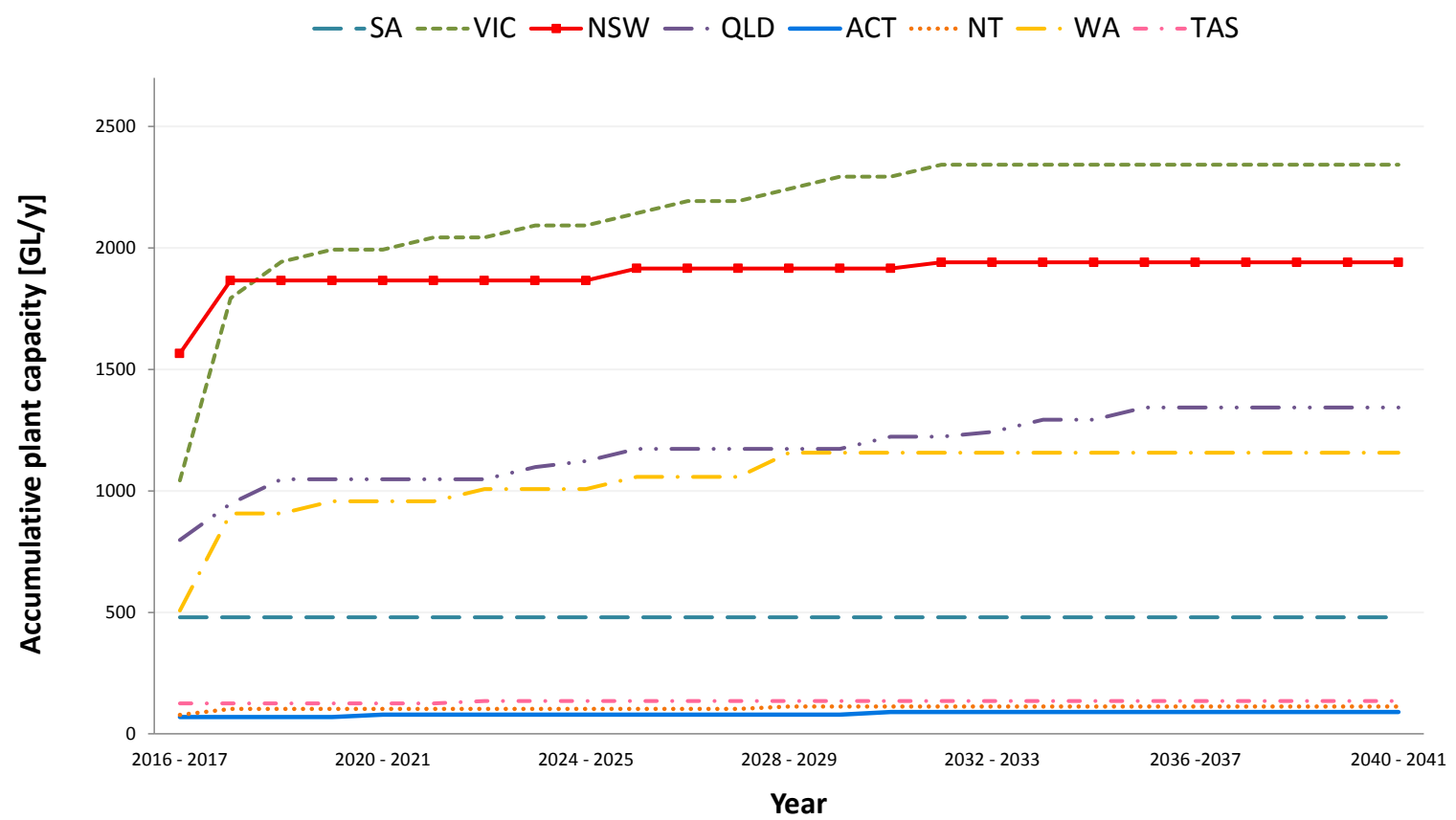

Figure 11: Total regional plant capacity expansions in the period $2016-2041$

Fig. 12 illustrates the regional water source mix in year 2040-2041. The size of the bubbles is relative to the total plants capacity in a state, meaning the bubbles, which are larger than the one in the legend, have a production capacity larger than $550 \mathrm{GL} /$ year and vice versa. The results show a portfolio of procured resource types where surface water plays a predominant role. Approximately $4 \%$ of the urban water demand in VIC and $2 \%$ in QLD is met through desalinated water. WA counts approximately $1 \%$ on seawater desalination while NT relies on $5 \%$ of groundwater. TAS and SA have solely surface water in their water mix to provide urban water supply. Fig. 12 resembles the regional water source mix presented in Fig. 5 for year 2014-2015, which shows an agreement with current practices as historical hydrological and availability data have been used with a final year 2015-2016. The reason for the slightly stronger preference towards surface water treatment can be explained not only with the cheapest purification cost but also with the extensive trading among the states. 


\section{Legend}

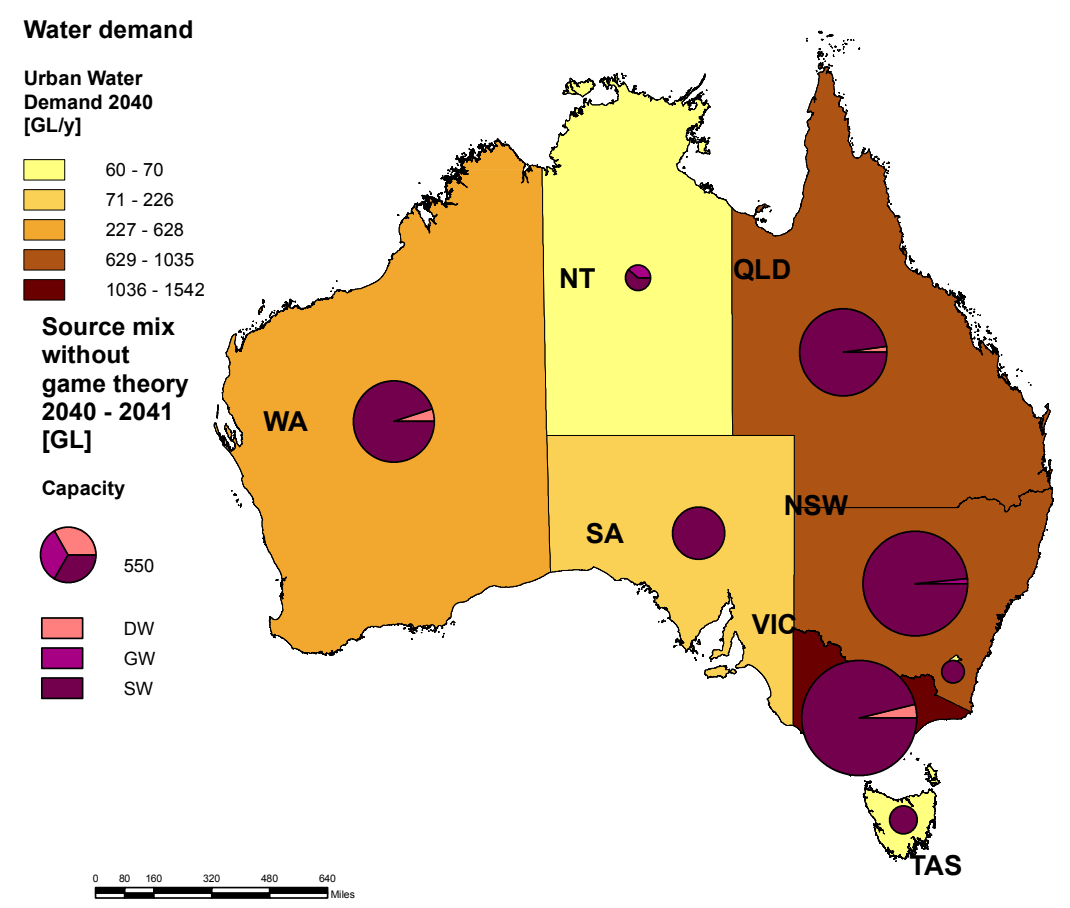

Figure 12: Water resource mix in 2040 - 2041

It has been allowed SA, VIC, NSW and QLD to be able to trade with its neighbouring states where there is a hydrological connection in MDB. Additionally, Sydney and Brisbane are isolated from trading and they are assumed to provide services only through their locally existing plants and through building new infrastructure. Surface water and groundwater, which are the current transferable sources in Australia, are allowed to be traded. The total surface water and groundwater volumes traded in and out from each state are depicted in Fig. 13(a) and Fig. 13(b), respectively, and summarised in Table 9 . The darker colour shades at the rim of the circles represent each state and the respective lighter coloured chords correspond to the flows that are sold by that state. The arc length is indicative of the amount of water sent out from that region. Hence, it can be deduced that the highest trading surface water activities take place between NSW $(72,047 \mathrm{GL}$ sold in total), VIC (51,449 GL sold in total) and SA (5,100 GL sold in total). On average, surface water trading provides from $8 \%$ up to $30 \%$ of the water demand in the country. In Fig. 13(b) the volumes as a whole are significantly lower which is due to the environmental restrictions for groundwater abstractions and to the greater costs associated with its treatment. The highest trading activities occur between NSW and QLD with a total sold groundwater of 29,898 GL and $29,903 \mathrm{GL}$, respectively. 


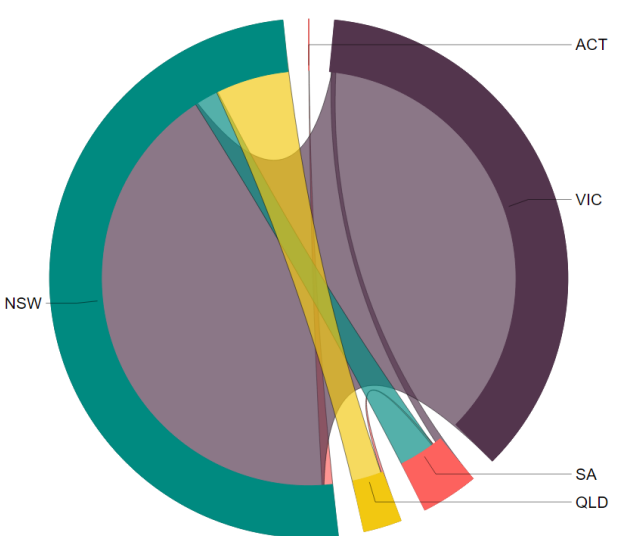

(a) Surface water trades

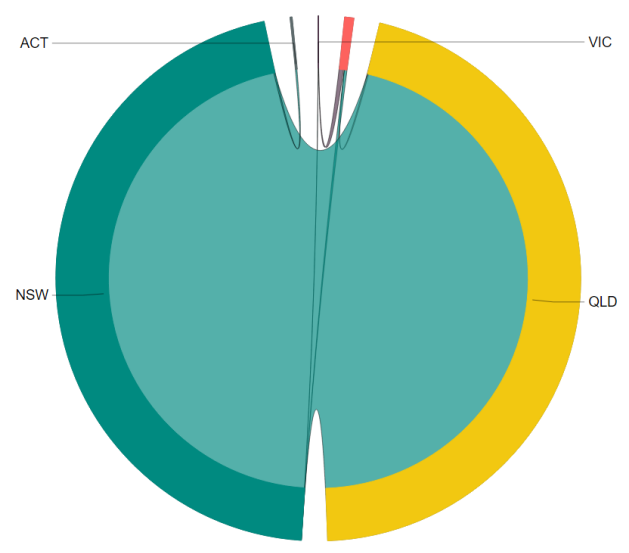

(b) Groundwater trades

Figure 13: Total traded volumes of water from state to state

Table 9: Regional total traded surface water and groundwater volumes for the 25-year planning horizon

\begin{tabular}{l|ccccc|ccccc}
\hline From/ & \multicolumn{5}{|c|}{ Surface water trades } & \multicolumn{5}{c}{ Groundwater trades } \\
$\quad$ To & SA & VIC & NSW & QLD & ACT & SA & VIC & NSW & QLD & ACT \\
\hline SA & & 861 & 4,001 & 236 & & & 228 & 139 & 8 & \\
VIC & 502 & & 50,947 & & & 0.1 & & 5 & & \\
NSW & 2,710 & 60,010 & & 8,161 & 1,166 & & 5 & & 29,815 & 78 \\
QLD & 269 & & 3,153 & & & 71 & & 29,832 & & \\
ACT & & & & & & & 85 & & & \\
\hline
\end{tabular}

The total regional costs arising from trading per year are shown in Fig. 14. In the figure, the positive values count towards a state's expenditures, while the negative values are the money received for selling water and they occur as profit. The low trading at the beginning of the planning horizon is due to the procurement of a region's own sources, such as groundwater and seawater. Surface water is in a higher demand in a dry year, therefore, more transfers happen in those periods, which, on the other hand are coupled with higher transfer prices. From Fig. 7 and Fig. 9 it can be deduced that periods 2018-2019, 2026-2029 and 2030-2034 are exposed to lower rainfalls and streamflows. In those periods, VIC has trading expenses varying up to to 0.28 bnUSD. On the contrary, NSW and QLD gain profit at various points throughout the planning horizon. 


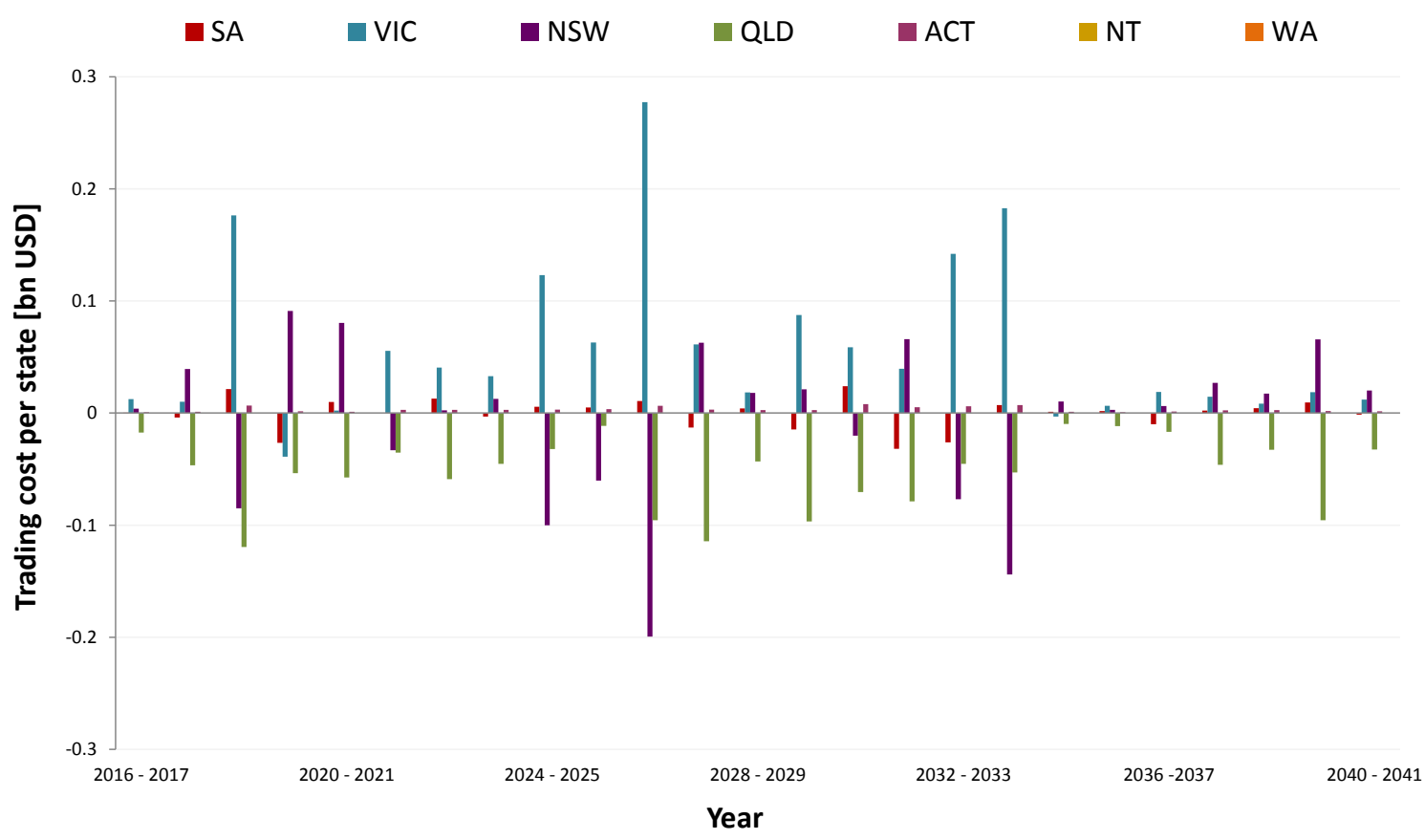

Figure 14: Regional trading transactions in the period 2016 - 2041

For a total cost of 327.94 bnUSD, the volumetric supply reliability for the country is $99.44 \%$. So far, Perth have investigated the water supply planning process and incurring costs at a targeted reliability of $90 \%$ [PMSEIC Working Group 2007], which is lower than the obtained value from the model. In years when rainfall is below average in conjunction with water production capacity shortage and increasing demand, reliability that high is uncommon. Further, it has been a historical practice for the industry to agree at an 'accepted level' of reliability with the urban communities, which involves temporal or volumetric restrictions households are subject to. Such an accepted level is set by the communities' willingness to pay for extra security of supply, which is difficult to determine [Hughes et al. 2009]. In order to explore a better and fairer trade-off between the two, the multiobjective optimisation solutions with $\varepsilon$-constraint method and game theory are discussed next.

\section{2. $\varepsilon$ - constraint multi-objective optimisation and Nash bargaining approach}

For the $\varepsilon$ - constraint method, 11 MILP problems are solved with an average CPU time of 11 seconds and a total CPU time of 120 seconds. At $W R=0$, the total cost contains the fixed operating cost of the existing plants, 159.6 bnUSD. Until 174.5 bnUSD, the total cost increases gradually while no capital expenditures from newly built plants contribute to it. That point corresponds to a supply reliability of $40 \%$. From that point onwards, the cost grows almost exponentially until it reaches 323.3 bnUSD with a maximum reliability achieved - $99.5 \%$. The obtained Pareto curve is plotted in Fig. 15, demonstrating all the optimal solutions, possible for the supply chain design and operation. The decision of the local governments and authorities to determine the point where they 
would like to stand is an intricate task. Hence, applying game theory can find the exact point where cost and reliability are at equilibrium.

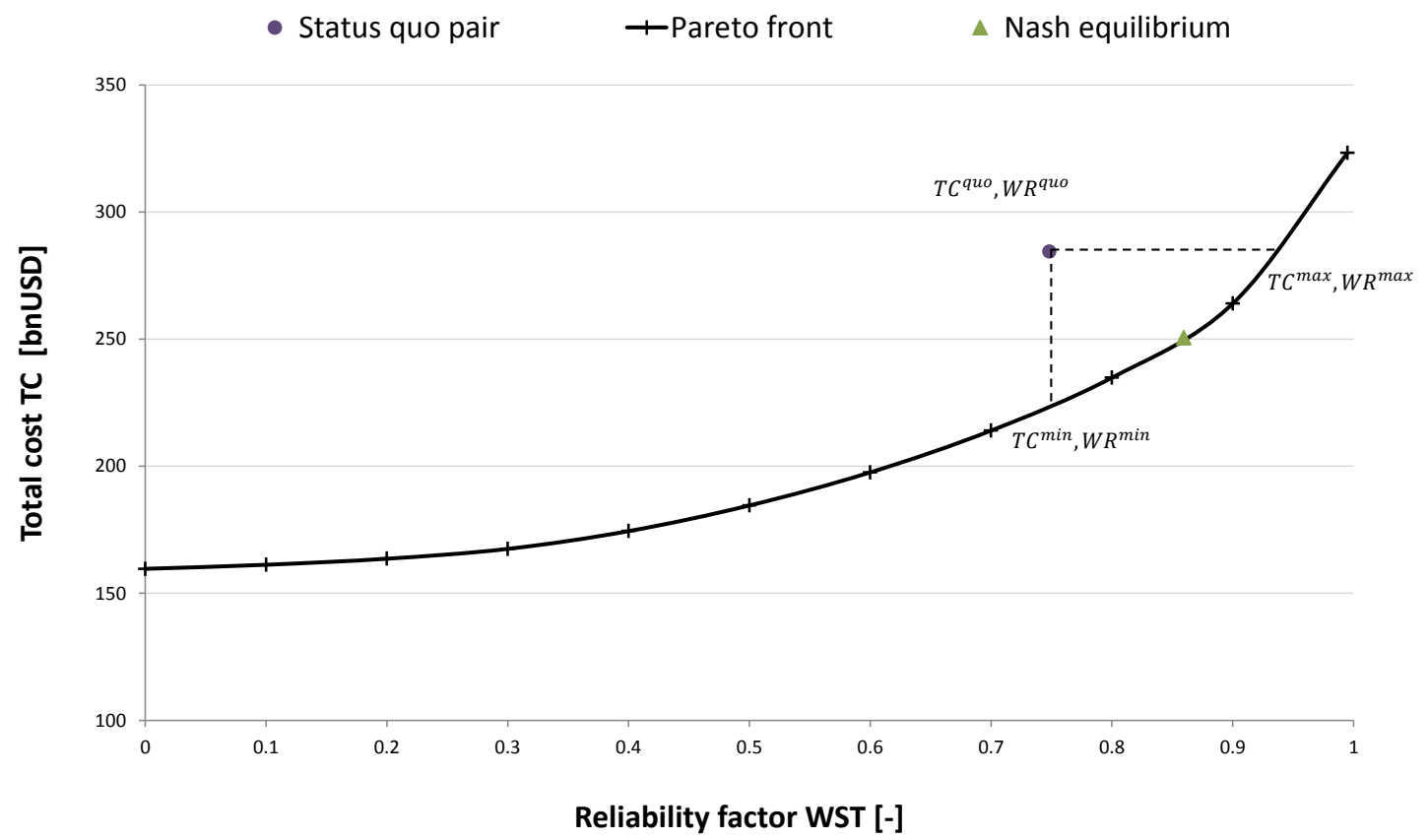

Figure 15: Nash bargaining solution on the Pareto curve

The choice of a status quo pair(s) $\left(W R^{q u o}, T C^{q u o}\right)$ in the Nash bargaining approach would define the outcome of the game theory. To select the two pay-offs, it is assumed no agreement can be settled between the two strategies, total cost and supply reliability. Hence, a worst case scenario is adopted where no improvement of reliability through building new infrastructure and water transfers can be achieved. Simultaneously, it is desired to maximise the reliability subject to the cost. $W R^{q u o}$ is equivalent to $W R^{\min }$ while $T C^{q u o}$ is equivalent to $T C^{\text {max }}$ (Fig. 15). In order to find out the negotiation set, where $W R^{q u o} \leq W R \leq W R^{\text {max }}$ and $T C^{\text {min }} \leq T C \leq T C^{q u o}$, and the pair $(W R, T C)$ is Pareto optimal, $W R^{\max }$ and $T C^{\min }$ are obtained. $W R^{\max }$ is the value obtained when reliability is maximised at $T C=T C^{\max }$ whereas $T C^{\min }$ is found by minimising the total cost subject to $W R=W R^{\min }$. The separable approach is executed using 100 discretisation points taken from $W R^{q u o}$ to $W R^{\max }$ and the corresponding points from $T C^{\mathrm{min}}$ to $T C^{q u o}$. The maximum bargaining solution is shown in Fig 15 and reported in Table 10

Table 10: Nash bargaining approach solutions

\begin{tabular}{lccc}
\hline & Objective values & & CPU [s] \\
& Water supply reliability WR [-] & Total cost TC [bnUSD] & 5 \\
\hline Status quo pair & 0.748 & 284.43 & $100 / 20$ \\
Max WR/ Min TC & 0.944 & 223.41 & 396 \\
Nash approach & 0.859 & 250.54 & 396 \\
\hline
\end{tabular}

From Fig. 15, it can be observed that the solution lies in the middle of the subset of optimal solutions 
considered. Reliability of $85.9 \%$ translates into a total cost of 250.54 bnUSD. The value for reliability has worsened by $14 \%$ and total cost value has improved by $25 \%$ from the monolithic approach. It must be noted that if a different methodology for deriving the status quo pair is used, the results obtained will differ.

The corresponding capacity expansions for the Nash equilibrium are illustrated in Fig. 16. From the figure, it can be deduced the expansions spread out throughout the planning horizon instead of taking place at its beginning, as seen in Fig. 11. At the end of the planning horizon VIC reaches a final total capacity of approximately 1,100 $\mathrm{GL} / \mathrm{y}, 1,200 \mathrm{GL} / \mathrm{y}$ less in comparison with the monolithic approach. QLD and WA reach production capacities of $1,342 \mathrm{GL} / \mathrm{y}$ and $1,108 \mathrm{GL} / \mathrm{y}$, respectively. As the supply reliability is normalised for the entire country, it is observed VIC undergoes largest cuts in reliability due to needed production capabilities.

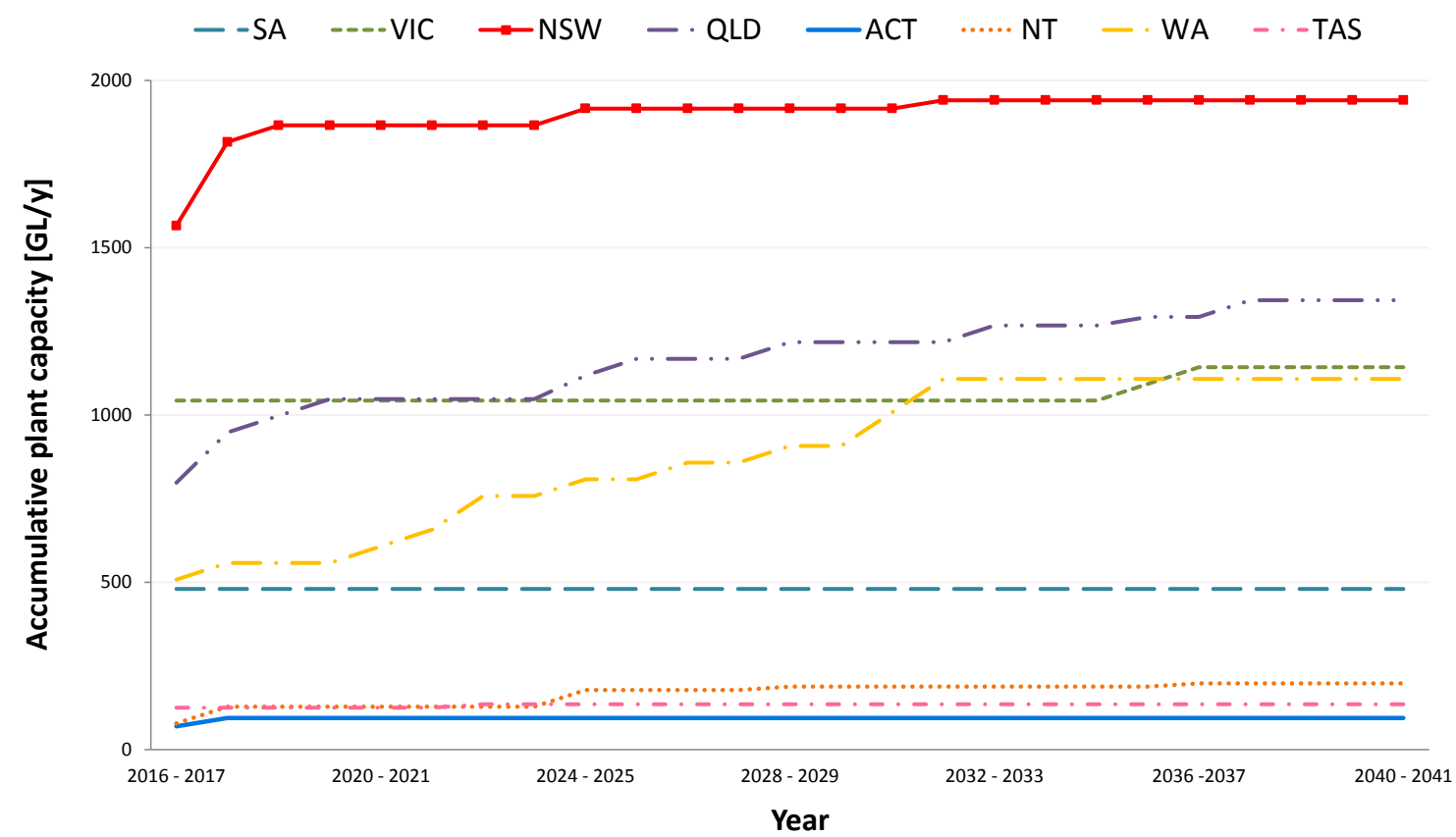

Figure 16: Total regional plant capacity expansions in the period 2016 - 2041 under game theory

The plants utilisations for the first and last year, for both, the monolithic approach and game theory, are shown in Fig. 17(a) and Fig. 17(b). From Fig. 17(a), it can be observed the difference of the plants utilisation in the monolithic approach and game theory throughout the first year of the planning horizon. The states which do not need to expand their capacities coincide roughly with their utilisation for both approaches which appears as a darker area in the figure. VIC and QLD build more capacities in the monolithic model opposed to importing water while in Nash bargaining approach not all of the available capacity in NSW is utilised in order for variable operating costs to be reduced. In 2040-2041, the radar shades coincide better for the two approaches. As demand increases and capacities have to be built, both models add capacities. It has already been seen, however, that for the game theoretic approach majority of the expansions happen in 2024-2030. Towards the end of the planning 


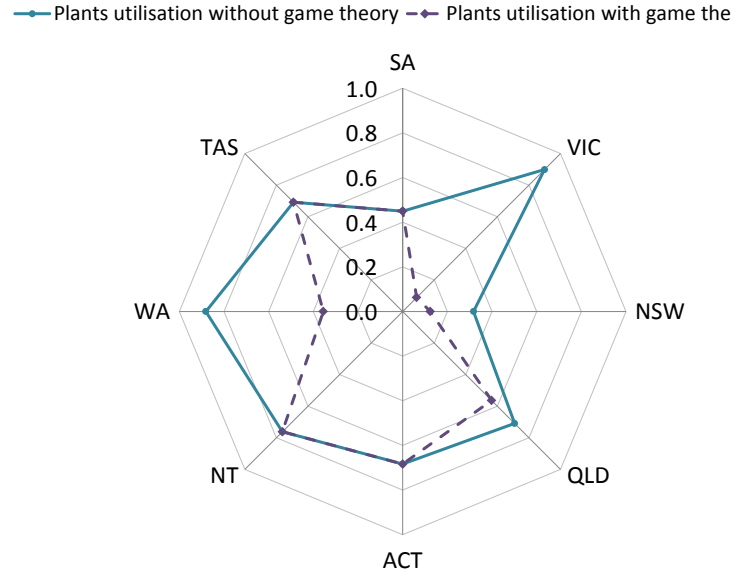

(a) Plants utilisation in 2016-2017

horizon, the reliability increases and hence, the utilisation profile of plants. Any shrinkages in the patterns are due to the augmented capacities of plants, which are operating at a higher production rate without reaching their full capacities. This is the case in VIC, for instance, where at the end of the planning horizon, the utilisation of plants has dropped from almost full operating capacity in 2016-2017 to $71 \%$ utilisation of plants in $2040-2041$ for the monolithic approach, and the utilisation has increased from $9 \%$ to $34 \%$ for the game theoretic approach.

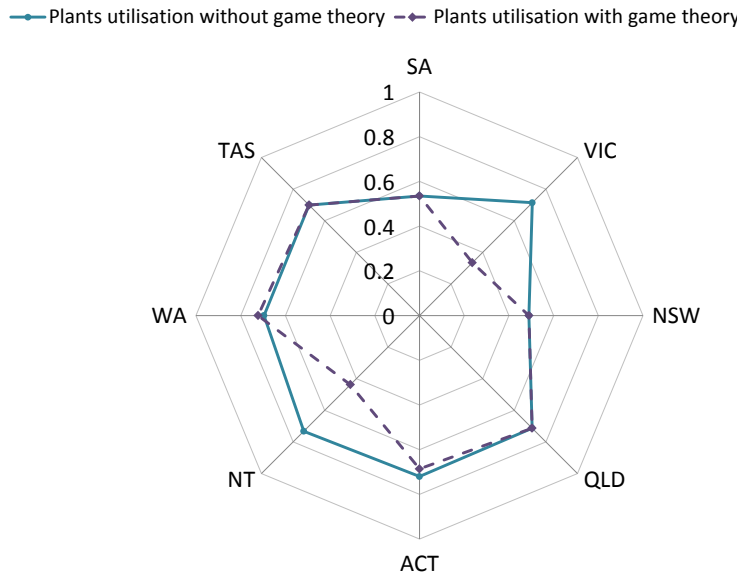

(b) Plants utilisation in 2040-2041
Figure 17: Plants utilisation for the first and last year of the planning horizon without and with game theory

\section{Pact of data variability}

\subsection{Impact of data variability}

The previous sections shed light on the economics of procurement, processing, and transportation of water resources to supply demand at the national scale. However, the data required in the analysis is inevitably subject to uncertainty which can have significant repercussions on the investment decisions and therefore the general economic performance of the water supply chain. Accordingly, this section elaborates on the effect of data variability on water supply chains. For this purpose, global sensitivity analysis (GSA) techniques are implemented [Sobol, 2001] in the context of supply chain applications [Caldern and Papageorgiou, 2018. In contrast to a conventional parametric analysis, GSA quantifies the individual and simultaneous effects of variations of a pool of parameters on the output variables. The case study discussed in Section 5.1 serves as basis for the analysis. The parameters selected for the GSA are: rainfalls, capital investments, facilities efficiency, and demand. In addition, a Probability Distribution Function (PDF) is required for each of the parameters in order to sample the uncertain space. In this case, we select the uniform distribution which assigns the same probability of realization to all the values that fall within a specific range for each of the parameters listed previously. Regarding the range of variation, rainfalls were considered to decrease up to $60 \%$ from the base case. Capital investments for new 
facilities were assumed to vary $\pm 30 \%$ from the base case in Section 5.1 whereas their efficiency was allowed to vary $\pm 5 \%$. Finally, a variation of $\pm 20 \%$ was assumed for the demand. The software SobolGSA Kucherenko et al. 2009] was used to carry out the sensitivity analysis. The uncertain space was sampled using a Quasi Monte Carlo method based on Sobol sequences [Kucherenko and Zaccheus, 2017]. The input data was correlated with the output variables via a Random Sampling-High dimensional model representation (RS-HDMR) method [Kucherenko and Zaccheus, 2017, Li et al. 2002]. This method allows to approximate the behaviour of complex models with few samples. In total, 256 scenarios were used in the analysis to generate sensitivity indices for first order and total effects. First order effects measure the variation on an output variable with respect to the variation of an input parameter. Total effects quantify the variation of an output variable due to an uncertain parameter and its interaction with the other uncertain parameters.

The results are summarised in Figure 18 where the colour of the bubbles represents first order effects of the varied parameters while the size of the bubbles represents the total effect of the parameters. The 256 scenarios result in total costs ranging from 288.1 bnUSD to 370.0 bnUSD with a median of 328.5 bnUSD differing $1 \%$ from the objective function of the initial problem. In the worst case scenario, urban water production from groundwater and seawater desalination is, respectively, 3.3 and 6.2 times higher than the best case scenario. Consequently, the capacity investments increase 4 times from the best to the worst case scenario due to solely surface and groundwater plants build. The regions which are affected are the Northern Territory and the Australian Capital Territory where the extreme cases account for, respectively, 3.7 and 3.3 fold increase in capacity expansions. NT, specifically, can suffer from severe droughts due to its geographical location and deserted land. Trading in active states increases substantially from the best to the worst scenario where the largest differences in total net trades is observed in New South Wales. The result aligns with the expectation of trading as a medium for mitigating the extreme climatic conditions and population projections in populated areas. 


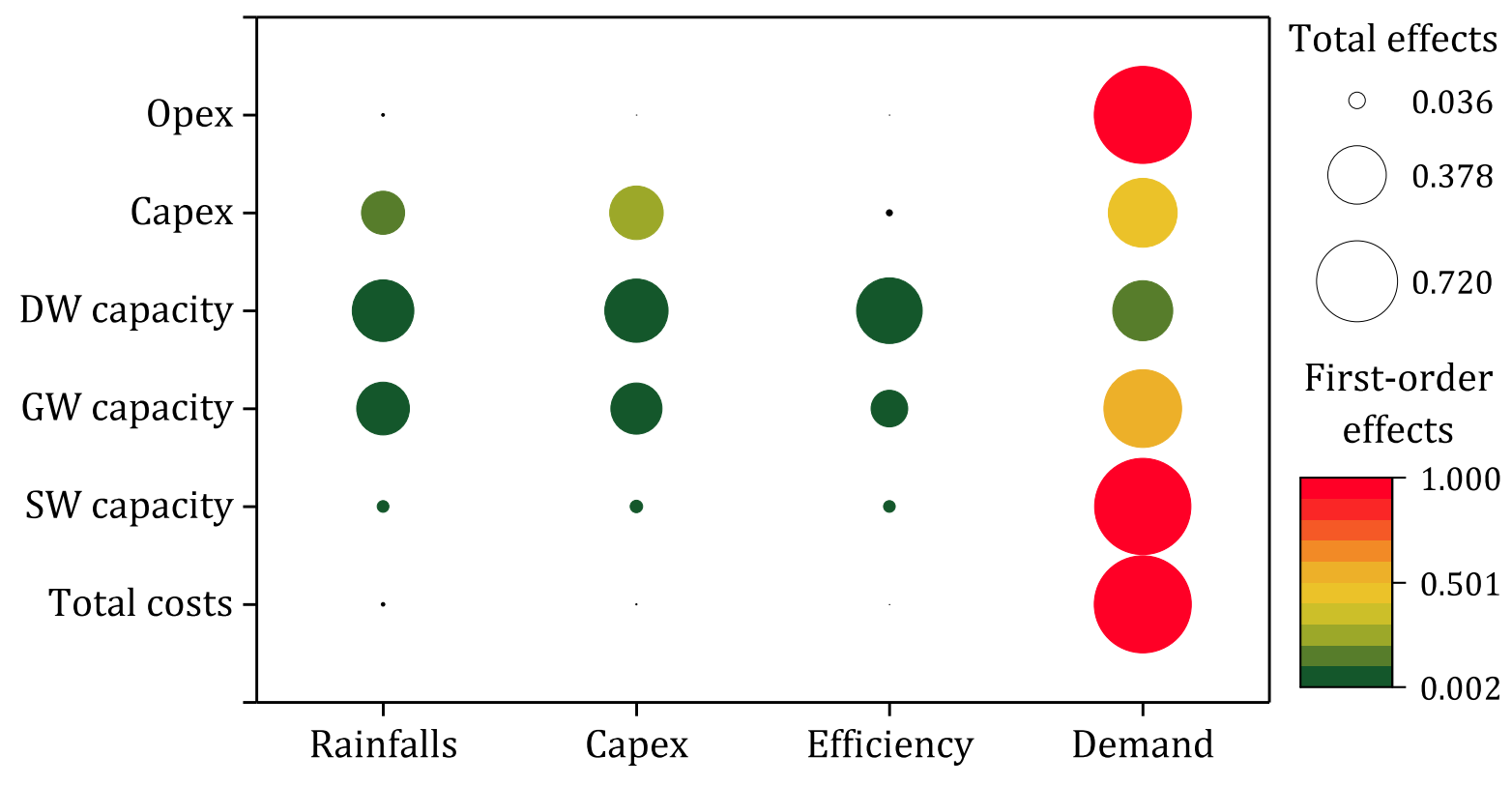

Figure 18: First-order and total effects of the Global Sensitivity Analysis

The results demonstrate that the urban water demand exerts an extensive impact on the water system cost. In particular, demand dominates in surface water capacity installations as they are the most economical decisions to demand response while the lack of precipitation, for instance, will not encourage the further build of SW plants. The uncertainty of building groundwater and seawater desalination facilities is influenced by the variability in demand but also in the uncertainty of rainfalls and plants' efficiencies. For the GW plants' capacity decisions demand still prevails with a total effect index of 0.65 , followed by rainfalls and efficiency of 0.30 and 0.14 , respectively. Contrarily, the two latter input variances contribute mostly to DW plants' build with total effect indices of 0.41 (rainfalls) and 0.46 (efficiency) while demand's index is estimated at 0.38 . The first-order effects variance of total CAPEX is influenced almost $50 \%$ by demand and the rest by rainfalls (20\%) and varying of the cost factors (30\%). The economics of the water supply chain is, therefore, least dependent of the operating plant efficiency. However, it represents a significant role in desalination where the purification process is associated with a higher unit cost.

\subsection{Benefits and limitations of the proposed model}

Following from the mathematical formulation presented in Section 3 and the results discussed in Sections 5.1 and 5.2. the optimisation model is subject to a number of strengths and limitations summarised as follows:

\section{Benefits:}

- The optimisation model solves within 10 minutes which makes it not computationally expensive. 
- Environmental, regulatory, technical and economic aspects are all integrated in a singular formulation which allows for more holistic decision.

- The multi-objective formulations allow a range of Pareto optimal and equilibrium options for decision makers. In this manner, regulators have a set of choices and they are aware a decision will result in higher cost/higher reliability and vice versa.

- The problem is easily expandable to additional sources, end-users, types of plants, cost components, etc.

\section{Limitations:}

- The intricacy of acquiring extensive data arises a set of various assumptions which determine the behaviour and accuracy of the model's results.

- The current formulation could be extended to include more detailed granularity, climate models for prediction in order to improve results quality.

- Currently, trading costs amongst regions are ignored which may affect traded flows. Therefore, game theory on regions as players will refine the trading decisions within the country.

\section{Concluding remarks}

A spatially-explicit multi-period Mixed Integer Linear Programming (MILP) model has been developed for the design and management of water supply chain within 'cap and trade' trading schemes. A novel mathematical framework is presented that considers climate variables through hydrological balances and allocation schemes in the optimisation of water resources management. Decisions entail the volumes and time periods for production capacity expansions in order to meet urban water demand. Reliability of water supply has been included in the monolithic mathematical formulation, which has become the second objective function in a multi-objective formulation using epsilon-constraint method. The trade-off between total cost and reliability has been determined by using the Nash bargaining approach. The applicability of the model has been investigated through a case study based on Australia.

Key findings suggest a trend in plants expansions and trading can keep surface water as the major source in the next 25 years. The possibility of all the neighbouring states situated on Murray-Darling Basin to trade, offers the advantage of providing surface water and groundwater in periods of drought. Supply reliability increases towards the end of the planning horizon, when larger capacities for conventional sources are in place. The application of game theory results in $25 \%$ lower total cost and $14 \%$ lower supply reliability compared to the single objective formulation. These optimal results from game theory indicate the sacrifices in total cost and supply reliability to 
obtain the fair design between the two objectives. The decisions for capacity expansions are spread out throughout the planning horizon unlike what is observed in the monolithic approach where the decisions are concentrated in the first part of the planning horizon.

Global Sensitivity Analysis (GSA) has been performed in order to concurrently address the effect of uncertainty in 4 parameters: demand, cost, rainfalls and plants' efficiencies. It has been shown that demand exhibits the highest impact on the water supply chain variables. Rainfalls and costs, especially in the cases of groundwater and seawater desalination build, contribute to variations similar in magnitude to demand. Efficiency plays the least significant role in the variation of the 4 parameters. When costly production, such as SW desalination, is considered, efficiency's total effect index increases vastly. The set of results presented in this work can assist decision makers to plan more insightfully water management systems.

\section{Acknowledgements}

The authors would like to acknowledge the financial support of BHP Billiton and data provision by the Australian Bureau of Meteorology.

\section{Appendix A.}

\section{Nomenclature}

Indices

$g, g^{\prime}$ states with a maximum number of states $G^{\max }$

$i, i^{\prime} \quad$ resources (surface water (sw), groundwater (gw), desalinated water (dw), urban water (uw))

$k \quad$ discrete options for separable approach

$l \quad$ capacity option levels for installation or expansion

$m \quad$ trading prices options

$p \quad$ plants

$q \quad$ seasonal time periods with a maximum number of seasons $Q^{\max }$

$t \quad$ yearly time periods with a maximum number of years $T^{\max }$

Sets

$\eta_{i g g^{\prime}}$ a set of neighbourhood for trading flows 
$I \quad$ a set of water resources where $I=S \cup W$

$L W$ a set of land sources (sw, gw)

$N P$ a set of newly installed plants

$P G_{g}$ a set of plants in a state $g$

$S \quad$ a set of water sources (sw, gw, dw)

$S P_{i} \quad$ a set of plants treating a specific source $s$

W a set of water product (uw)

Parameters

$\varepsilon_{i^{\prime} i p}$ efficiency for plant $p$ for source of water $i^{\prime}$ for production of product $i,[-]$

$\lambda_{k} \quad$ parameter expressing the natural logarithm of reliability difference for an option $k,[-]$

$\xi_{k} \quad$ parameter expressing the natural logarithm of cost difference for an option $k,[-]$

capdam $_{l}$ cost factors for building dams with capacity level $l,[b n U S D / G L]$

$\operatorname{capexp}_{p l}$ cost factors for extending plant $p$ with capacity level $l,[b n U S D / G L]$

caplant $_{p l}$ cost factors for building plant $p$ with capacity level $l,[b n U S D / G L]$

$c d f_{t}$ capital costs discount factor, $[b n U S D / y]$

$d c t$ time for building a new dam, $[y]$

dem $_{\text {igtq }}$ demand for a product $w$ in region $g$ at time $t,[G L / y]$

$d f f_{g}$ factor accounting for water distribution losses due to leakages in a region $g,[-]$

$d s f$ factor for minimum reservoir storage, $[-]$

$E^{\max }$ maximum number of expansions, $[-]$

$\operatorname{ecap}_{p l}$ expansion capacity of plant $p$ for level $l,[G L / y]$

$e c t_{p}$ time for expanding a new plant $p,[y]$

ent $_{\text {igt }}$ entitlements of water source $i$ in a region $g$ at time $t,[G L / y]$

fop $_{\text {plt }}$ fixed operating costs for plant $p$ at capacity level $l$ at time $t,[b n U S D / G L]$ 
icap $_{p l}$ installation capacity of plant $p$ for level $l,[G L / y]$

ict $_{p} \quad$ time for installing a new plant $p,[y]$

idam $_{g l t}$ installation capacity of dam for level $l$ in region $g$ at time $t,[G L]$

$L_{\text {igtq }}$ evaporation in a region $g$ at times $t$ and $q,[G L]$

$L R_{i g t q}^{a i n}$ land rainfall in a region $g$ at times $t$ and $q,[G L]$

$M \quad$ big number, $[G L / y]$

ocap $_{p}$ installed capacity of plant $p$ at the beginning of the planning horizon, $[G L / y]$

$o d f_{t}$ operating costs discount factor, $[b n U S D / y]$

oldam $_{g t}$ existing capacity of dams in region $g$ at time $t,[G L]$

oldplant $_{p}$ existing capacity of plants, $[G L / y]$

$p c$ penalty cost for not meeting urban water demand, $[b n U S D / G L]$

$R_{i g t q}^{a i n}$ direct rainfall to storage in a region $g$ at times $t$ and $q,[G L]$

$r^{\text {infl infiltration coefficient, }[-]}$

$R_{i g t q}^{i v e r}$ streamflows in a region $g$ at times $t$ and $q,[G L]$

$R_{\text {igtq }}^{\text {unoff }}$ runoff in a region $g$ at times $t$ and $q,[G L]$

$R_{i g t q}$ hydrological water inflows in a region $g$ at times $t$ and $q$, $[G L]$

$S P_{i g t}^{\max }$ maximum sustainable yield of source $s$ in a region $g$ at time $t,[G L / y]$

$\operatorname{trc}_{g}$ selling transaction cost, $[b n U S D / G L]$

$\operatorname{trpr}_{g t m}$ water selling price for region $g$ at time $t$ and option $m,[b n U S D / G L]$

up utilisation fraction of water which is collected and directed to wastewater treatment plants, $[-]$

$\operatorname{vod}_{t}$ variable cost factor for operating dams at time $t,[b n U S D / G L]$

vop $_{p l t}$ variable operating costs for plant $p$ at capacity level $l$ at time $t,[b n U S D / G L]$

$W R^{*}$ epsilon values for $\varepsilon$-constraint solution approach, $[-]$

$W S R_{i g}^{\min }$ minimum water reliability of region $g,[-]$ 


\section{Binary variables}

$B_{\text {igtq }}$ binary variable equal to 1 in the year $t$ and season $q$ when supply exceeds demand, [-]

$E_{g p l t}$ binary variable equal to 1 if capacity level $l$ of plant $p$ in region $g$ at time $t$ is expanded, [-]

$I_{g p l t}$ binary variable equal to 1 if capacity level $l$ of plant $p$ in region $g$ at time $t$ is installed, [-]

$I D_{g l t}$ binary variable equal to 1 if capacity level $l$ of dam in region $g$ at time $t$ is installed, [-]

$Y_{g t m}$ binary variable equal to 1 if a price in a region $g$, time $t$ and option $m$ is selected, [-]

SOS variables

$X_{k}$ an SOS type 2 variable equal to 1 if an option $k$ for cost and reliability is selected, [-]

\section{Continuous variables}

$\bar{\tau} \quad$ non-linear objective function for Nash bargaining approach, $[-]$

$\hat{\tau} \quad$ linear objective function for Nash bargaining approach, $[-]$

$\hat{Q}_{i g g^{\prime} t q m}$ discrete traded flows of water $i$ from a region $g$ to a region $g^{\prime}$ at time $t$ and $q$ for option $m,[G L / y]$

$A_{\text {igtq }}$ allocations of source $i$ in region $g$ at time $t,[G L / y]$

$A C_{i g t q}$ carry over for source $s$ in region $g$ at time $t,[G L / y]$

CAPEX $X_{t}$ total capital expenditure at time $t,[b n U S D / y]$

$C D A M_{t}$ dams capital expenditure at time $t,[b n U S D / y]$

$C P L_{t}$ plant capital expenditure for installation at time $t,[b n U S D / y]$

$D_{\text {igtq }}$ demand of a water source or end use $i$ in a region $g$ at time $t,[G L / y]$

$D A M_{g t}$ capacity of dams in region $g$ at time $t,[G L]$

$D S_{i g t q}$ dams storage of water $i$ in a region $g$ at times $t$ and $q,[G L]$

$O_{\text {igtq }}$ outflow of water $i$ in a region $g$ at times $t$ and $q,[G L]$

$O D A M_{t}$ dams operational expenditure at time $t,[b n U S D / y]$

$\mathrm{OPen}_{t}$ penalty cost at time $t,[b n U S D / y]$

$O P E X_{t}$ total operational expenditure at time $t,[b n U S D / y]$ 
$O P L_{t}$ plant operational expenditure at time $t,[b n U S D / y]$

$O T R_{t}$ trading expenditure at time $t,[b n U S D / y]$

$P_{\text {igtq }}$ production of a water source or end use $i$ in a region $g$ at time $t,[G L / y]$

$P D_{\text {igtq }}$ penalty for unmet demand for source $i$, region $g$ and time $t,[G L]$

$Q_{i g g^{\prime} t q}$ traded flows of water $i$ from a region $g$ to a region $g^{\prime}$ at time $t$ and $q,[G L / y]$

$R C_{i g t q}$ recharge of water $i$ in a region $g$ at times $t$ and $q,[G L]$

$S S_{\text {igtq }}$ overall storage of water $i$ in a region $g$ at times $t$ and $q$, $[G L]$

$T C$ total capital and operating costs for the entire planning horizon, [bnUSD]

$T C A P_{g p t}$ capacity of plant $p$ in region $g$ at time $t,[G L / y]$

$\operatorname{trp}_{g t}$ water selling price for region $g$ at time $t,[b n U S D / G L]$

$V_{\text {igptq }}$ plant intake of source $s$ in region $g$ in period $t,[G L / y]$

$W R$ total reliability of water supply, [-]

$W S_{i g t q}$ natural water storage $i$ in a region $g$ at times $t$ and $q$, $[G L]$

$W S R_{\text {igtq }}$ supply reliability of water $i$ in a region $g$ at times $t$ and $q,[-]$

\section{References}

M. T. Al-Nory and S. C. Graves. Water desalination supply chain modelling and optimization. In 2013 IEEE 29th International Conference on Data Engineering Workshops (ICDEW), pages 173-180, April 2013. doi: 10.1109/ICDEW.2013.6547447.

American Planning Association, editor. Planning and urban design standards, volume 1. John Wiley \& Sons, Inc., New Jersey, United States, 1 edition, 2006. ISBN 10:0-471-47581-5.

L. Amodeo, C. Prins, and D. R. Sánchez. Comparison of Metaheuristic Approaches for Multi-objective SimulationBased Optimization in Supply Chain Inventory Management, pages 798-807. Springer Berlin Heidelberg, Berlin, Heidelberg, 2009. doi: 10.1007/978-3-642-01129-0_90. 
Australian Bureau of Meteorology. El Niño Southern Oscillation (ENSO), 2008. URL http://www.bom.gov. au/climate/about/?bookmark=enso. Accessed on 05/11/2016.

Australian Bureau of Meteorology. Australian climate variability \& change - time series graphs, 2016a. URL http://www.bom.gov.au/climate/change. Accessed on 13/08/2016.

Australian Bureau of Meteorology. Archive - monthly rainfall totals, 2016b. URL http://www.bom.gov.au/ jsp/awap/rain/index.jsp. Accessed on 13/08/2016.

Australian Bureau of Meteorology. Seasonal streamflow forecasts, 2016c. URL http://www.bom.gov.au/water/ ssf/index.shtml. Accessed on 16/12/2016.

Australian Bureau of Meteorology. Water market information, 2016d. URL http://www . nationalwatermarket. gov.au/site-information/water-words.html. Accessed on 21/08/2016.

Australian Bureau of Meteorology. Water storage, 2017. URL http://water.bom.gov.au/waterstorage/ awris/ Accessed on 18/01/2017.

Australian Bureau of Statistics. Water account, Australia, 2013-2014, 2015a. URL http://www.abs.gov.au/ AUSSTATS/abs@.nsf/DetailsPage/4610.02013-14?OpenDocument Accessed on 15/04/2016.

Australian Bureau of Statistics. Water account, Australia, 2014-2015, 2015b. URL http://www.abs.gov.au/ AUSSTATS/abs@.nsf/DetailsPage/4610.02014-15?OpenDocument. Accessed on 02/02/2017.

Australian Government. Cost-benefit analysis of current and proposed dams in GBR catchments, 2014. URL http://agwhitepaper.agriculture.gov.au/GP\%20Submissions\%20for\%20publication/ GP284\%20WWF_Part\%202.pdf. Accessed on 17/11/2016.

Australian Government. Water market information, 2016a. URL http://www.nationalwatermarket.gov.au/ about/index.html. Accessed on 24/02/2016.

Australian Government. National major desalination plants database, 2016b. URL https://data.gov.au/ dataset/national-major-desalination-plants-database Accessed 12/04/2016.

Australian Government. The Great Artesian Basin: Water in the Dry Interior, 2016c. URL http://www. agriculture.gov.au/SiteCollectionDocuments/water/great-artesian-basin-teacher-kit.pdf. Accessed on $09 / 01 / 2017$.

Australian Government. State and territory government, 2017. URL http://www.australia. gov.au/about-government/how-government-works/state-and-territory-government. Accessed on 01/02/2017. 
R. F. Banaszewski, L. V. Arruda, J. M. Simo, C. A. Tacla, A. P. Barbosa-Póvoa, and S. Relvas. An application of a multi-agent auction-based protocol to the tactical planning of oil product transport in the Brazilian multimodal network. Computers \& Chemical Engineering, 59:17 - 32, 2013. doi: http://dx.doi.org/10.1016/j.compchemeng. 2013.06.007.

J. F. Bard, J. Plummer, and J. C. Sourie. A bilevel programming approach to determining tax credits for biofuel production. European Journal of Operational Research, 120(1):30 - 46, 2000. ISSN 0377-2217. doi: http://dx.doi.org/10.1016/S0377-2217(98)00373-7.

R. E. Barlow. Mathematical theory of reliability: A historical perspective. IEEE Transactions on Reliability, R-33 (1):16-20, 1984. doi: 10.1109/TR.1984.6448269.

M. Blanco and M. Viladrich-Grau. The introduction of a water rights trading scheme in the Segre Basin and the contribution of reused irrigation water. ITEA, 110(4):374-399, 2014.

C. Brebbia, editor. Water Resources Management VIII, volume 8. WITPress, Wessex Institute, UK, 2015. ISBN 978-1-84564-960-9.

W. Britz, M. Ferris, and A. Kuhn. Modeling water allocating institutions based on multiple optimization problems with equilibrium constraints. Environmental Modelling \& Software, 46:196 - 207, 2013. doi: http://dx.doi.org/ 10.1016/j.envsoft.2013.03.010.

A. J. Caldern and L. G. Papageorgiou. Key aspects in the strategic development of synthetic natural gas (biosng) supply chains. Biomass and Bioenergy, 110:80 - 97, 2018. ISSN 0961-9534. doi: https://doi.org/10.1016/j. biombioe.2018.01.004.

California Urban Water Agencies. California urban water agencies water supply reliability report, 2012. URL http://www. cuwa.org/pubs/CUWA_WaterSupplyReliability.pdf. Accessed on 22/03/2017.

H. Campbell and R. Brown. Benefit-Cost Analysis. Financial and Economic Appraisal using Spreadsheets, volume 1. Cambridge University Press, Cambridge, United Kingdom, 2003. ISBN 978-0-521-52898-6.

Z. Chen and S. Andresen. A multiobjective optimization model of production-sourcing for sustainable supply chain with consideration of social, environmental, and economic factors. Mathematical Problems in Engineering, 2014: 1 - 11, 2014. doi: doi:10.1155/2014/616107.

R. Clark, D. Gonzalez, P. Dillon, S. Charles, D. Cresswell, and B. Naumann. Reliability of water supply from stormwater harvesting and managed aquifer recharge with a brackish aquifer in an urbanising catchment and 
changing climate. Environmental Modelling \& Software, 72:117 - 125, 2015. doi: http://dx.doi.org/10.1016/j. envsoft.2015.07.009.

N. W. Commission. Australian water markets report 2009-10, 2010. URL http://www.mdba.gov.au/kid/ files/1795\%20-\%20Australian\%20Water\%20Markets\%20R_2009-2010.pdf. Accessed on 11/01/2017.

E. Damelin, U. Shamir, and N. Arad. Engineering and economic evaluation of the reliability of water supply. Water Resources Research, 8(4):861-877, 1972. ISSN 1944-7973. doi: 10.1029/WR008i004p00861.

Department of Natural Resources, Environment, the Arts and Sport. Ti tree basin water resource report, 2009. URL https://denr.nt.gov.au/__data/assets/pdf_file/0019/254602/basin_water_ resource_report_09.pdf. Accessed on 09/01/2017.

P. Dizikes. Water problems in Asia's future?, 2016. URL http://news.mit.edu/2016/ water-problems-asia-0330. Accessed on 29/10/2016.

T. Erfani, I. Huskova, and J. J. Harou. Tracking trade transactions in water resource systems: A node-arc optimization formulation. Water Resources Research, 49(5):3038-3043, 2013. ISSN 1944-7973. doi: 10.1002/ wrcr.20211.

T. Erfani, O. Binions, and J. J. Harou. Simulating water markets with transaction costs. Water Resources Research, 50(6):4726-4745, 2014. doi: 10.1002/2013WR014493.

J. Finch and A. Calver. Methods for the quantification of evaporation from lakes prepared for the world meteorological organization's commission for hydrology, 2008. URL http://nora.nerc.ac.uk/14359/1/wmoevap_ 271008.pdf. Accessed on 15/01/2017.

J. Gjerdrum, N. Shah, and L. G. Papageorgiou. Fair transfer price and inventory holding policies in two-enterprise supply chains. European Journal of Operational Research, 143(3):582 - 599, 2002. doi: http://dx.doi.org/10. 1016/S0377-2217(01)00349-6.

I. Goulter. Analytical and Simulation Models for Reliability Analysis in Water Distribution Systems, pages 235266. Springer Netherlands, Dordrecht, 1995. doi: 10.1007/978-94-017-1841-7_10. URL http://dx.doi.org/ 10.1007/978-94-017-1841-7_10

O. J. Guerra, A. J. Caldern, L. G. Papageorgiou, J. J. Siirola, and G. V. Reklaitis. An optimization framework for the integration of water management and shale gas supply chain design. Computers \& Chemical Engineering, 92:230 - 255, 2016. doi: http://dx.doi.org/10.1016/j.compchemeng.2016.03.025. 
N. Harrington and P. Cook. Groundwater in Australia, 2014. URL http://www.groundwater.com.au/media/ W1siZiIsIjIwMTQvMDMvMjUvMDFfNTFfMTNfMTMzXOdyb3VuZHdhdGVyX2luXOF1c3RyYWxpYV9GSU5BTF9mb3Jfd2ViLnBkZiJdX Groundwater\%20in\%20Australia_FINAL\%20for\%20web.pdf. Accessed on 09/01/2017.

D. Hawk. Water supply reliability, 2003. URL http://www.science.calwater.ca.gov/pdf/water_supply. pdf. Accessed on 22/03/2017.

X. He, H. Zheng, and S. Peeta. Model and a solution algorithm for the dynamic resource allocation problem for large-scale transportation network evacuation. Transportation Research Part C: Emerging Technologies, 59:233 - 247, 2015. doi: http://dx.doi.org/10.1016/j.trc.2015.05.005.

O.-F. Heydari, M. and K. Qaderi. Developing optimal reservoir operation for multiple and multipurpose reservoirs using mathematical programming. Mathematical Problems in Engineering, 2015:1-11, 2015. doi: 10.1155/ $2015 / 435752$.

N. Hughes, A. Hafi, and T. Goesch. Urban water management: optimal price and investment policy under climate variability*. Australian Journal of Agricultural and Resource Economics, 53(2):175-192, 2009. doi: 10.1111/j.1467-8489.2007.00446.x.

W. J. B. A. B. Hughes, Trevor C.; Grenney. Capability of integer programming algorithms in solving water resource planning problems, 1976. URL http://digitalcommons.usu.edu/water_rep/394. Accessed on $26 / 01 / 2017$.

Independent Pricing and Regulatory Tribunal. Review of water prices for Sydney Desalination Plant Pty Limited, 2011. URL https://www.ipart.nsw.gov.au/files/cb824878-2ece-4fa4-86ba-9fb400a8238a/ Final_Report_-_Review_of_water_prices_for_Sydney_Desalination_Plant_Pty_Limited_-_From_ 1_July_2012_-_December_2011_-_Website_Document.pdf. Accessed on 17/10/2016.

International Commission on Large Dams. Role of dams, 2016. URL http://www.icold-cigb.net/GB/Dams/ role_of_dams.asp. Accessed on 20/08/2016.

S. Joshi and R. Joshi, editors. Designing and Implementing Global Supply Chain Management, volume 1. Business Science Reference, Hershey, 1 edition, 2016. ISBN 9781466697201.

M. N. Koleva, E. M. Polykarpou, S. Liu, C. A. Styan, and L. G. Papageorgiou. Optimal design of water treatment processes. Desalination and Water Treatment, 57(56):26954-26975, 2016. doi: 10.1080/19443994.2016. 1173595. 
M. N. Koleva, C. A. Styan, and L. G. Papageorgiou. Optimisation approaches for the synthesis of water treatment plants. Computers \& Chemical Engineering, pages -, 2017. doi: http://dx.doi.org/10.1016/j.compchemeng.2016. 12.018 .

E. Kondili, J. Kaldellis, and C. Papapostolou. A novel systemic approach to water resources optimisation in areas with limited water resources. Desalination, 250(1):297 - 301, 2010. doi: http://dx.doi.org/10.1016/j.desal.2009. 09.046 .

S. Kucherenko and O. Zaccheus. Sobolgsa software, 2017. URL http://www.imperial.ac. uk/process-systems-engineering/research/free-software/sobolgsa-software/. Accessed on 01/11/2016.

S. Kucherenko, M. Rodriguez-Fernandez, C. Pantelides, and N. Shah. Monte carlo evaluation of derivative-based global sensitivity measures. Reliability Engineering and System Safety, 94:1135 - 1148, 2009. ISSN 0951-8320. doi: http://dx.doi.org/10.1016/j.ress.2008.05.006.

Legislative Assembly Committee. Data on water trading in Western Australia, 2000. URL http://www.parliament.wa.gov.au/Parliament/commit.nsf/(Evidence+Lookup+by+Com+ID) /2F59FD83CFBEAA75482578310040CF0D/\$file/Submission+No+46+Dept+of+Water.pdf. Accessed on $31 / 01 / 2017$.

G. Li, S.-W. Wang, and H. Rabitz. Practical approaches to construct rs-hdmr component functions. The Journal of Physical Chemistry A, 106(37):8721-8733, 2002. doi: 10.1021/jp014567t.

M. Li, P. Guo, V. P. Singh, and J. Zhao. Irrigation water allocation using an inexact two-stage quadratic programming with fuzzy input under climate change. Journal of the American Water Resources Association, 52(3):667-684, 2016. doi: 10.1111/1752-1688.12415.

Y. P. Li, G. H. Huang, and S. L. Nie. Water resources management and planning under uncertainty: an inexact multistage joint-probabilistic programming method. Water Resources Management, 23(12):2515-2538, 2009. doi: 10.1007/s11269-008-9394-x.

S. Liu. Supply Chain Management for the Process Industry. PhD thesis, University College London, 2011.

S. Liu and L. G. Papageorgiou. Multiobjective optimisation of production, distribution and capacity planning of global supply chains in the process industry. Omega, 41(2):369 - 382, 2013. doi: http://dx.doi.org/10.1016/j. omega.2012.03.007. 
S. Liu, P. Gikas, and L. G. Papageorgiou. An optimisation-based approach for integrated water resources management. volume 28, pages 1075 - 1080. 2010. doi: http://dx.doi.org/10.1016/S1570-7946(10)28180-4.

S. Liu, P. Gikas, and L. G. Papageorgiou. A two-step optimisation approach for integrated water resources management. Computer Aided Chemical Engineering, 30:96 - 100, 2012. doi: http://dx.doi.org/10.1016/ B978-0-444-59519-5.50020-4.

S. Liu, F. Konstantopoulou, P. Gikas, and L. G. Papageorgiou. A mixed integer optimisation approach for integrated water resources management. Computers \& Chemical Engineering, 35(5):858-875, 2011. doi: 10.1016/j.compchemeng.2011.01.032.

D. P. Loucks, E. van Beek, J. R. Stedinger, J. P. Dijkman, and M. T. Villars. Water Resources Systems Planning and Management: An Introduction to Methods, Models and Applications. UNESCO, Paris, France, 1st edition, 2005.

A. T. . M. V. M. Daumas, E. Martin-Dorel. A formal theory of cooperative TU-games, pages 81-91. Springer Berlin Heidelberg, Berlin, Heidelberg, 2009. URL https://pdfs.semanticscholar.org/2cd3/ 40e1bcd636700d0df1435db32030b174f8cb.pdf. Accessed on 08/01/2017.

K. Madani. Game theory and water resources. Journal of Hydrology, 381(34):225 - 238, 2010. doi: http: //dx.doi.org/10.1016/j.jhydrol.2009.11.045.

D. R. Maidment, S.-P. Miaou, and M. M. Crawford. Transfer function models of daily urban water use. Water Resources Research, 21(4):425-432, 1985. doi: 10.1029/WR021i004p00425.

E. S. Matrosov, I. Huskova, J. R. Kasprzyk, J. J. Harou, C. Lambert, and P. M. Reed. Many-objective optimization and visual analytics reveal key trade-offs for londons water supply. Journal of Hydrology, 531, Part 3:1040 1053, 2015. doi: http://dx.doi.org/10.1016/j.jhydrol.2015.11.003.

J. Morrison, M. Morikawa, M. Murphy, and P. Schulte. Water scarcity \& climate change: Growing risks for business \& investors, 2009. URL http://www2.pacinst.org/wp-content/uploads/2013/02/full_report30.pdf Accessed on $29 / 10 / 2016$.

Murray-Darling Basin Commission. Murray-darling basin groundwater-a resource for the future, 1999. URL http://wWw.mdba.gov.au/sites/default/files/archived/mdbc-GWreports/2173_GW_a_ resource_for_the_future.pdf. Accessed on 09/01/2017.

J. Nash. The bargaining problem. Econometrica, 18:155 - 162, 1950. doi: 10.2307/1907266. 
A. Nikjoofar and M. Zarghami. Water distribution networks designing by the multiobjective genetic algorithm and game theory. In X.-S. Yang, A. H. Gandomi, S. Talatahari, and A. H. Alavi, editors, Metaheuristics in Water, Geotechnical and Transport Engineering, pages 99 - 119. Elsevier, Oxford, 2013. doi: http://dx.doi.org/10.1016/ B978-0-12-398296-4.00005-2.

OECD. Managing water for all. an OECD perspective on pricing and financing, 2009. URL http://www. oecd. org/tad/sustainable-agriculture/44476961.pdf. Accessed on 23/03/2017.

R. A. Ortiz-Gutierrez, S. Giarola, N. Shah, and F. Bezzo. An approach to optimize multi-enterprise biofuel supply chains including Nash equilibrium models. volume 37, pages 2255-2260, 2015. doi: 10.1016/ B978-0-444-63576-1.50070-4.

S. Padula. Capacity expansion modelling to aid water supply investment decisions. PhD thesis, University College London, 2015.

S. Padula, J.J.Harou, L.G.Papageorgiou, Y.Ji, M.Ahmad, and N.Hepworth. Least economic cost regional water supply planning optimising infrastructure investments and demand management for South East England's 17.6 million people. Water Resources Management, 27(15):5017 - 5044, 2013. doi: 10.1007/s11269-013-0437-6.

Y. Peng, J. Chu, A. Peng, and H. Zhou. Optimization operation model coupled with improving water-transfer rules and hedging rules for inter-basin water transfer-supply systems. Water Resources Management, 29(10): 3787-3806, 2015. doi: 10.1007/s11269-015-1029-4.

C. Pira and C. Artigues. Line search method for solving a non-preemptive strictly periodic scheduling problem. Journal of Scheduling, 19(3):227-243, 2016. doi: 10.1007/s10951-014-0389-6.

J. Pita, M. Jain, M. Tambe, F. Ordez, and S. Kraus. Robust solutions to Stackelberg games: Addressing bounded rationality and limited observations in human cognition. Artificial Intelligence, 174(15):1142 - 1171, 2010. doi: http://dx.doi.org/10.1016/j.artint.2010.07.002.

Planning Institute Australia. Policy. water and planning, 2016. URL https://www.planning.org.au/policy/ water-and-planning. Accessed on 29/10/2016.

PMSEIC Working Group. Water for our cities: building resilience in a climate of uncertainty, 2007. URL https: //industry.gov.au/science/PMSEIC/Documents/WaterforOurCities.pdf. Accessed on 27/03/2017.

S. Pokharel. A two objective model for decision making in a supply chain. International Journal of Production Economics, 111(2):378 - 388, 2008. doi: http://dx.doi.org/10.1016/j.ijpe.2007.01.006. 
Pricewaterhouse Coopers. Infrastructure Australia. Review of urban water security strategies May 2010, 2010. URL http://infrastructureaustralia.gov.au/policypublications/publications/files/ UrbanWaterSecurityReportForInfrastructureAustralia.pdf. Accessed on 13/03/2016.

M. E. Qureshi, S. M. Whitten, M. Mainuddin, S. Marvanek, and A. Elmahdi. A biophysical and economic model of agriculture and water in the Murray-Darling Basin, Australia. Environmental Modelling \& Software, 41:98 106, 2013. doi: http://dx.doi.org/10.1016/j.envsoft.2012.11.007.

P. A. Ray, P. H. Kirshen, and R. M. Vogel. Integrated optimization of a dual quality water and wastewater system. Journal of Water Resources Planning and Management, 136(1):37-47, 2010. doi: 10.1061/(ASCE) WR.1943-5452.0000004.

J.-D. Rinaudo, J. Calatrava, and M. V. De Byans. Tradable water saving certificates to improve urban water use efficiency: an ex-ante evaluation in a French case study. Australian Journal of Agricultural and Resource Economics, 60(3):422-441, 2016. doi: 10.1111/1467-8489.12132.

R. Roozbahani, B. Abbasi, and S. Schreider. Optimal allocation of water to competing stakeholders in a shared watershed. Annals of Operations Research, 229(1):657 - 676, 2015. doi: 10.1007/s10479-015-1806-8.

E. C. Rosenthal. A game-theoretic approach to transfer pricing in a vertically integrated supply chain. International Journal of Production Economics, 115(2):542 - 552, 2008. doi: http://dx.doi.org/10.1016/j.ijpe.2008.05.018.

Y. Saif and A. Almansoori. Design and operation of water desalination supply chain using mathematical modelling approach. Desalination, 351:184 - 201, 2014. doi: http://dx.doi.org/10.1016/j.desal.2014.07.037.

Y. Saif and A. Almansoori. A capacity expansion planning model for integrated water desalination and power supply chain problem. Energy Conversion and Management, 122:462 - 476, 2016. doi: http://dx.doi.org/10. 1016/j.enconman.2016.06.011.

G. M. Sechi, R. Zucca, and P. Zuddas. The Water Pricing Problem in a Complex Water Resources System: A Cooperative Game Theory Approach, pages 511-516. Springer Berlin Heidelberg, Berlin, Heidelberg, 2011. doi: 10.1007/978-3-642-20009-0_81.

U. Shamir. Reliability of Water Supply Systems, pages 233-248. Springer Netherlands, Dordrecht, 1987. doi: 10.1007/978-94-009-3577-8_13.

R. B. Shelton, editor. Gaming the Market. Applying Game Theory to Create Winning Trading Strategies, volume 1. John Wiley \& Sons, INC, New York, 1 edition, 1997. ISBN 0471168130. 
D. Simchi-Levi, S. Wu, and S. Z.M., editors. Handbook of Quantitative Supply Chain Analysis, volume 74. Springer, New York, US, 2004. doi: 10.1007/978-1-4020-7953-5.

S. Simonit, J. P. Connors, J. Yoo, A. Kinzig, and C. Perrings. The impact of forest thinning on the reliability of water supply in central arizona. Plos One, 10(4):1-21, 04 2015. doi: 10.1371/journal.pone.0121596.

I. Sobol. Global sensitivity indices for nonlinear mathematical models and their monte carlo estimates. Mathematics and Computers in Simulation, 55(1):271 - 280, 2001. ISSN 0378-4754. doi: https://doi.org/10.1016/ S0378-4754(00)00270-6. The Second IMACS Seminar on Monte Carlo Methods.

S. Souza, J. Medellín-Azuara, N. Burley, J. Lund, and R. Howitt. Guidelines for preparing economic analysis for water recycling projects, 2011. URL https://watershed.ucdavis.edu/files/biblio/EAGD_Final_ V2003_05182011.pdf. Accessed on 18/08/2016.

F. A. Souza Filho, U. Lall, and R. L. L. Porto. Role of price and enforcement in water allocation: Insights from game theory. Water Resources Research, 44(12), 2008. doi: 10.1029/2007WR006163.

State Government Victoria. Future farming systems research division, 2011. URL http://www . dairyaustralia. com.au/ /media/Documents/Stats $\% 20$ and $\% 20$ markets/Farm\%20facts/Dairy\%20Dierctions $\% 20-\%$ 20Irrigation\%20re-use\%20dams.pdf. Accessed on 17/10/2016.

M. Tambe, editor. Security and Game Theory. Algorithms, Deployed Systems, Lessons Learned, volume 1. Cambridge University Press, New York, 1 edition, 2012. ISBN 9781107096424.

The Allen Consulting Group. Transaction costs of water markets and environmental policy instruments, 2006. URL http://wWw.pc.gov.au/inquiries/completed/water-study/transaction-costs/ waterstudyreport.pdf. Accessed on 30/01/2017.

M. H. K. Tushar, C. Assi, M. Maier, and M. F. Uddin. Smart Microgrids: Optimal Joint Scheduling for Electric Vehicles and Home Appliances. IEEE Transactions of Smart Grid, 5(1):239-250, JAN 2014. doi: 10.1109/TSG. 2013.2290894.

Urban Water Cycle Solutions. Costs of water grids with security infrastructure next, 2015. URL http:// urbanwatercyclesolutions.com/watergridcosts1/. Accessed on 15/11/2016.

US Environmental Protection Agency. International climate impacts, 2016. URL https://www.epa.gov/ climate-impacts/international-climate-impacts. Accessed on 29/10/2016.

P. Vaillant. Water, Kimberley/ Canning Basin, 2015. URL http://organicsocieties.org/index.php/ 2-c-8-calculation-of-the-water-necessary-for-shale-gaz-in-the-canning-basin-included- 1 

on $09 / 01 / 2017$.

J. Veintimilla-Reyes, D. Cattrysse, A. D. Meyer, and J. V. Orshoven. Mixed integer linear programming (MILP) approach to deal with spatio-temporal water allocation. Procedia Engineering, 162:221 - 229, 2016. doi: http://dx.doi.org/10.1016/j.proeng.2016.11.045.

Victorian Water Register. Allocation trading, 2017. URL http://waterregister.vic.gov.au/ water-trading/allocation-trading. Accessed on 20/02/2017.

Y. Wang and S.-K. Au. Spatial distribution of water supply reliability and critical links of water supply to crucial water consumers under an earthquake. Reliability Engineering \& System Safety, 94(2):534 - 541, 2009. doi: http://dx.doi.org/10.1016/j.ress.2008.06.012.

D. Whittington, W. Hanemann, C. Sadoff, and M. Jeuland. The Challenge of Improving Water and Sanitation Services in Less Developed Countries, Foundations and Trends in Microeconomics, volume 4. Publishers Inc., Hanover, United States, 2008. ISBN 978-1-60198-248-3.

M. K. Wittholz, B. K. O'Neill, C. B. Colby, and D. Lewis. Estimating the cost of desalination plants using a cost database. Desalination, 229(13):10 - 20, 2008. doi: http://dx.doi.org/10.1016/j.desal.2007.07.023.

XE. Xe currency converter, 2016. URL http://www.xe.com/currencyconverter/ Accessed on 29/07/2016.

D. Yang, J. R. Jiao, Y. Ji, G. Du, P. Helo, and A. Valente. Joint optimization for coordinated configuration of product families and supply chains by a leader-follower Stackelberg game. European Journal of Operational Research, 246(1):263 - 280, 2015. doi: http://dx.doi.org/10.1016/j.ejor.2015.04.022.

U. Yildiran, I. Kayahan, M. Tunç, and S. Sisbot. MILP based short-term centralized and decentralized scheduling of a hydro-chain on Kelkit River. International Journal of Electrical Power \& Energy Systems, 69:1 - 8, 2015. doi: http://dx.doi.org/10.1016/j.ijepes.2014.12.082.

Z. Yin. Addressing Uncertainty in Stackelberg Games for Security: Models and Algorithms. PhD thesis, University of Southern California, 2013.

D. G. Yoo, D. Kang, and J. H. Kim. Optimal design of water supply networks for enhancing seismic reliability. Reliability Engineering \& System Safety, 146:79 - 88, 2016. doi: http://dx.doi.org/10.1016/j.ress.2015.10.001.

D. Yue and F. You. Game-theoretic modeling and optimization of multi-echelon supply chain design and operation under Stackelberg game and market equilibrium. Computers \& Chemical Engineering, 71:347 - 361, 2014. ISSN 0098-1354. doi: http://dx.doi.org/10.1016/j.compchemeng.2014.08.010. 
M. A. Zamarripa, A. M. Aguirre, C. A. Mndez, and A. Espua. Mathematical programming and game theory optimization-based tool for supply chain planning in cooperative/competitive environments. Chemical Engineering Research and Design, 91(8):1588 - 1600, 2013. doi: http://dx.doi.org/10.1016/j.cherd.2013.06.008.

X. Zeng, Y. Li, G. Huang, and L. Yu. Inexact mathematical modeling for the identification of water trading policy under uncertainty. Water, 6(2):229-252, 2014. doi: 10.3390/w6020229. URL http://www.mdpi.com/ $2073-4441 / 6 / 2 / 229$.

D. Zhang, N. J. Samsatli, A. D. Hawkes, D. J. Brett, N. Shah, and L. G. Papageorgiou. Fair electricity transfer price and unit capacity selection for microgrids. Energy Economics, 36:581 - 593, 2013. doi: http://dx.doi.org/ 10.1016/j.eneco.2012.11.005.

D. Zhang, Y. Alhorr, E. Elsarrag, A. H. Marafia, P. Lettieri, and L. G. Papageorgiou. Fair design of CCS infrastructure for power plants in Qatar under carbon trading scheme. International Journal of Greenhouse Gas Control, 56:43 - 54, 2017. doi: http://dx.doi.org/10.1016/j.ijggc.2016.11.014.

Q. Zhu, J. Gould, Y. Li, and C. Ma, editors. Rainwater Harvesting for Agriculture and Water Supply, volume 74. Springer Singapore, Singapore, 1 edition, 2015. doi: 10.1007/978-981-287-964-6. 